\title{
$L g$ wave propagation in the area around Japan: observations and simulations
}

\author{
Takashi Furumura ${ }^{1 *}$, Tae-Kyung Hong ${ }^{2}$ and Brian LN Kennett ${ }^{3}$
}

\begin{abstract}
Regional wavefields are strongly influenced by crustal structure heterogeneity variations along their propagation paths. Observations of such effects between the Asian continent and the Japanese subduction zone across the Sea of Japan (East Sea) have been strongly assisted recently by the development of high-density seismic networks in Japan and Korea, as well as the supercomputer-based three-dimensional finite difference method seismic wave propagation simulations using detailed heterogeneous crustal models. In this study, an $L g$ propagation map derived from 289,000 ray paths connecting sources to observation stations reveals efficient $L g$ wave propagation from continental Asia to Kyushu through the Korean Peninsula, and to Hokkaido, thus indicating a laterally consistent crustal structure extending from continental Asia to Japan. However, the $L g$ wave propagation to the Japanese main island of Honshu is totally blocked as it crosses the continental-oceanic boundary surrounding the Sea of Japan. Three-dimensional (3-D) finite-difference method seismic wave propagation simulations performed using a detailed crustal structural model allow us to clearly visualize the way in which an $\mathrm{L} g$ wave develops from a shallow source in the crust and its propagation in the crustal waveguide by means of multiple post-critical $S$ wave reflections in the continental structure. The sudden thinning of the continental crust at the edge of the Asian continent adjacent to the oceanic crust in the Sea of Japan, which involves a thickness change from 30 to $10 \mathrm{~km}$ within a 100-km distance (with the thinner crust extending over $600 \mathrm{~km}$ ), decreases the $\mathrm{Lg}$ wave energy by $10 \%$. It has been confirmed that $50 \%$ of this $L g$ wave energy loss occurs during wave passage along the thinner crust and that the other $50 \%$ results from conversion into $P$ energy in the overlying seawater.
\end{abstract}

Keywords: Computational seismology; Crustal structure; Finite-difference method simulation; Lg wave; Regional wave; Sn wave; Wave propagation

\section{Background}

An $L g$ wave is a crustally guided $S$ wave composed of a superposition of post-critical reflections in the crust such as that between a free surface and the Mohorovičić discontinuity (Moho), which can also be interpreted as a combination of higher-mode surface waves. In the short-period seismograms, an $L g$ wave is usually a prominent feature at regional distances from $150 \mathrm{~km}$ to well over $1,000 \mathrm{~km}$ from the hypocenter of the event in continental structures and can be identified on three-component seismograms by the amplitude similarities of each component. The phase is dominated by relatively high frequencies between 0.2 and $5 \mathrm{~Hz}$. Therefore, $L g$ phases have been

\footnotetext{
* Correspondence: furumura@eri.u-tokyo.ac.jp

'Earthquake Research Institute, The University of Tokyo, 1-1-1 Yayoi,

Bunkyo-ku, Tokyo 113-0032, Japan

Full list of author information is available at the end of the article
}

used to magnitude estimates of shallow events $\left(m_{b}(L g)\right.$, see, e.g., Nuttli 1973; Herrmann and Nuttli 1982) and to map crustal heterogeneities by estimating $L g$ attenuation variations $\left(Q_{L g}\right.$; e.g., Phillips et al. 2000; Xie et al. 2006; Chung et al. 2007; Hong et al. 2008). The $L g$ phase is also utilized for discriminating manmade sources from natural earthquakes, such as by using the $L g / P g$ and $L g / P n$ amplitude ratio (e.g., Kennett 1993; Walter et al. 1995; Taylor 1996; Fisk 2006; Kim and Richards 2007).

It is well recognized that $L g$ wave propagation is extremely sensitive to lateral crustal structure variations. For example, although $L g$ waves propagate efficiently from most areas of the Asian and Eurasian continents, strong attenuation and/or $L g$ wave blockage has been identified in a number of regions, such as southern Eurasia (Ruzaikan et al. 1977; Ni and Barazangi 1983), northwestern Russia (Baumgardt 1985), the Tibetan Plateau (Xie 2002; Fan and 
Lay 2003), the Himalaya-Tibet collision zone (Singh et al. 2012), and the Alpine Mountains (Campillo et al. 1987). In these cases, attenuation and/or blockage has been traced to the geological and tectonic environments of each region and to features such as abrupt lateral variations in the crustal thickness, thick sediment cover, low- $Q$ materials in the crust, or partial crustal melting.

The $L g$ phase can also be dramatically attenuated by the sudden crustal structural change from thick continental crust to thinner oceanic crust, and a distance as short as $100 \mathrm{~km}$ across oceanic crust is sufficient to eliminate $L g$ wave propagation (Press and Ewing 1952). Lg wave propagation is also inefficient in areas with thinner crust, such as the Mediterranean, Black Sea, southern Caspian Sea (Press and Ewing 1952; Kadinsky-Cade et al. 1981; Maupin 1989; Rodgers et al. 1997), and the North Sea Central Graben (Gregersen 1984; Kennett et al. 1985).

Such variations in the $\mathrm{Lg}$ wave propagation in different parts of the world have been studied extensively within the contexts of investigating crustal heterogeneity, monitoring nuclear explosion tests, and discriminating between such tests and natural shallow earthquakes, etc. However, considerably less study has been done in the areas surrounding Japan.

The Japanese Islands are unique in that they are situated on a continental crust surrounded by oceanic crust, which means that $L g$ waves develop along limited paths. However, the amplitude behavior of the $L g$ waves in such combined environments has not yet been fully investigated. Utsu (1956) identified the arrival of $L g$ waves in the Galitzin and Benioff long-period seismograms recorded in Japan and later (1958) examined $L g$ wave propagation from the epicenters of Asian earthquakes to Japan. His 1958 study demonstrated that the $L g$ waves propagate to Japan from continental Asia across the Yellow Sea and the northern part of the East China Sea, but he also noted that $L g$ wave propagation is totally blocked across the Sea of Japan (East Sea). Next, Shima (1962) examined the regional variations of $L g$ wave propagation in Japan and noticed that the $L g$ wave propagation speed in northeastern Japan $(3.57 \mathrm{~km} / \mathrm{s})$ is slightly faster than the propagation speed in southwestern Japan $(3.44 \mathrm{~km} / \mathrm{s})$.

In the 40 years that followed, little work on $L g$ propagation in Japan was undertaken until the studies of Furumura and Kennett (2001) and Kennett and Furumura (2001), who developed an $L g$ wave propagation map for Japan using short-period seismograms from the J-Array short-period seismic network that extends across Japan (Yomogida 1996). Their studies demonstrated regional variations in $L g$ wave propagation in Japan that are characterized by efficient $L g$ wave propagation in western Japan and relatively inefficient $L g$ wave propagation in northern Japan. They also demonstrated that the $L g$ wave propagation along the Japanese Islands is attenuated as the waves traverse the Pacific Ocean and Sea of Japan in areas where water depths exceed approximately 1,000 m. In 2001, Kennett and Furumura conducted a two-dimensional (2-D) finite-difference method (FDM) simulation of regional wavefields along the Japanese subduction zone in order to investigate the nature of $L g$ wave propagation in the Japanese Islands across the continent-ocean transition area.

More than 10 years have passed since our previous studies (Furumura and Kennett 2001; Kennett and Furumura 2001), and during this interval, there has been considerable progress in both seismic monitoring and available computational capabilities. Therefore, in this study, we revisit our former studies into the nature of $L g$ wave propagation in Japan, with special emphasis on $L g$ wave propagation from outside Japan to the Japanese Islands across the Sea of Japan using a large amount of waveform data obtained from recently deployed high-density seismic networks in Japan and Korea, and supercomputerbased three-dimensional (3-D) FDM simulation of regional wave propagation by the use of a high-resolution crustal structure model.

In this paper, we first revise and extend earlier works (Furumura and Kennett 2001; Hong 2010) into Lg wave propagation and then present a detailed $L g$ propagation map of the area around Japan, including Korea and parts of continental Asia. We then conducted a 3-D FDM simulation of the regional seismic wavefield in the area around Japan using the Earth Simulator supercomputer (The Earth Simulator Center, Yokoyama, Japan), which is operated by the Japan Marine Science and Technology Center (JAMSTEC) and using the recently released CRUST 1.0 crust model (Laske et al. 2013), in order to visualize the properties of the $L g$ wave propagation along the continental waveguide and the dissipation of the $L g$ waves caused by crustal barriers.

\section{Tectonic environment in the area around Japan}

The Japanese Islands are located in a tectonically complicated area where oceanic plates (the Pacific and Philippine Sea Plates) and continental plates (the North American and the Eurasian Plates) collide. As a result, the nation is subject to large numbers of earthquakes occurring along the plate boundaries and in the various plates. The northern half of the Japanese Islands are located on the North American Plate with the Pacific Plate subducting from the Japan Trench beneath northern and central Japan, which extends from Hokkaido to Honshu (Figure 1). The volcanic front associated with this subducting plate lies across the central Japanese island of Honshu, and a large number of active volcanoes extend from Hokkaido to central Honshu (Figure 1). The western part of the Japanese Islands is located on the Eurasian Plate of the Asian continent, where the Philippine Sea Plate subducts at a 


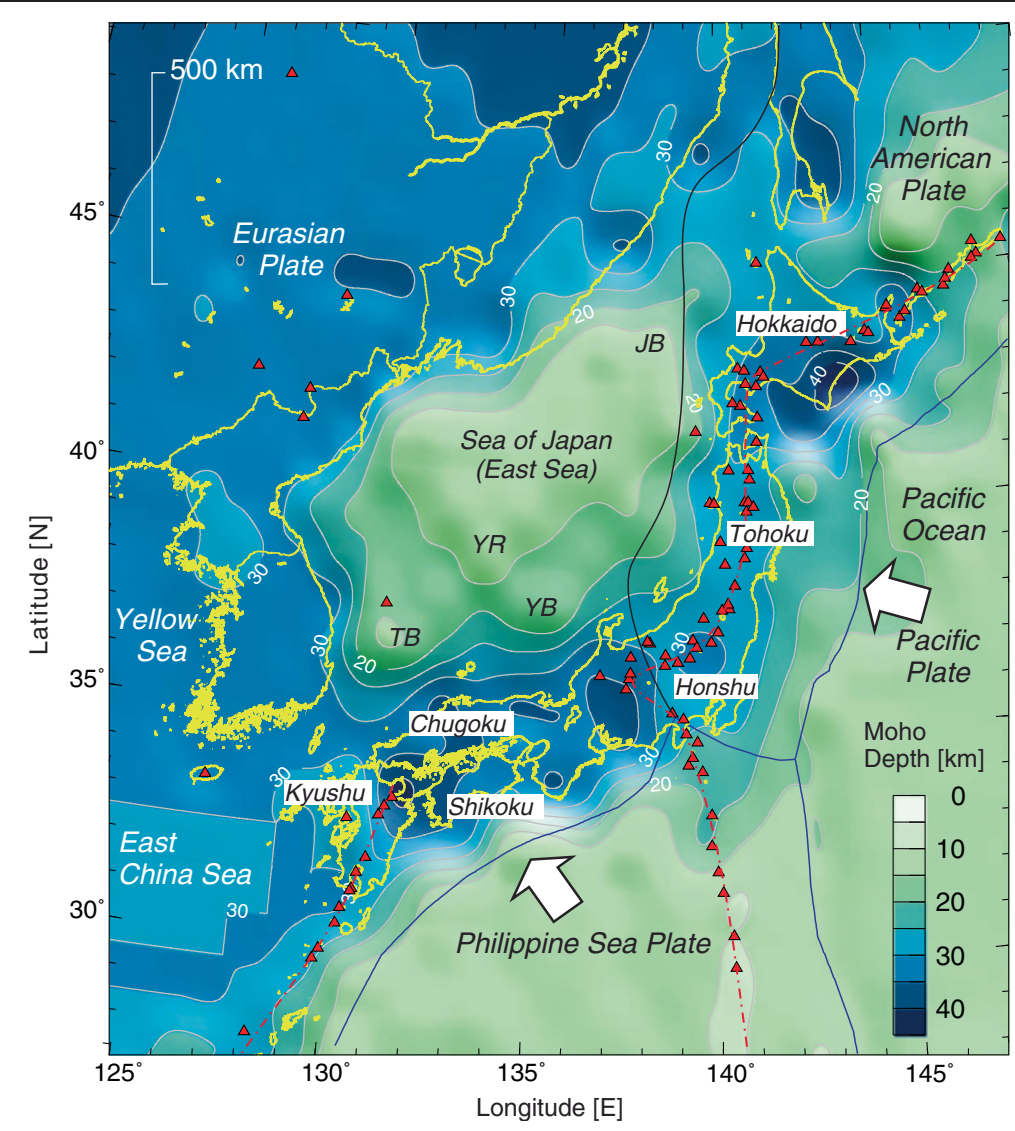

Figure 1 Tectonic environment and crust thickness in the area around Japan. Tectonic environment in the area around Japan. The blue lines denote the plate boundaries, and the gray lines illustrate the isodepth contours of the Moho depth in kilometers derived from the CRUST 1.0 model (Laske et al. 2013). The red triangles and lines denote active volcanoes and the volcanic front, respectively. The major features in the Sea of Japan are marked as follows: JB, Japan Basin; YB, Yamato Basin; TB, Tsushima Basin; YR, Yamato Rise.

relatively gentle $\left(<10^{\circ}\right.$ to 20$)$ angle beneath Shikoku and Chugoku Islands, but at a much steeper $\left(>50^{\circ}\right)$ angle beneath Kyushu. The line of the volcanic front in western Japan lies across Kyushu and the Ryukyu Islands, where many active volcanoes are present; however, no volcanic front exists on the Shikoku or Chugoku Island. Therefore, the crustal structure of western Japan is more like a continental structure where efficient $L g$ wave propagation can be expected, similar to most areas of the Asian and Eurasian continents.

The Sea of Japan is a marginal sea surrounded by continental Asia, the Korean Peninsula, and the Japanese Islands. Here, an oceanic basin developed due to continental rifting during the Oligocene to mid-Miocene periods, at which time the Japanese Islands separated from the Eurasian Plate. However, the exact formation and evolution of the Sea of Japan remains with the subject of various proposed models, including an explanation involving a fan-shaped opening with different arc rotations (e.g., Otofuji et al. 1991), and a hypothesis that the Sea of Japan's formation was due to a pull-apart opening along the share zone in the eastern and western margins of the sea (e.g., Lallemand and Jolivet 1985). Based on an analysis of paleo-magnetic data (Otofuji et al. 1991), the age of the opening of the Sea of Japan has been estimated at 12 to $21 \mathrm{Ma}$.

The isodepth contour of the Moho depth derived from a recently released crustal model (CRUST 1.0) (Laske 2013) shows a transitional structure for the Sea of Japan with a thicker $(>10 \mathrm{~km})$ crust than is normal for ocean areas (about 5 to $7 \mathrm{~km}$ ), but which is much thinner than the crust of the surrounding continental regime (about 30 to $35 \mathrm{~km}$ ). There is a rapid transition in the Moho depth from continental structure (around $30 \mathrm{~km}$ ) to approximately $20 \mathrm{~km}$ along the Sea of Japan border. The average and maximum water depths in the Sea of Japan are about 2 and $3.6 \mathrm{~km}$, respectively, which are still much shallower than the depth of the Pacific Ocean to the east and south of the Japanese Islands (Figure 2).

In contrast to the thick $(>35 \mathrm{~km})$ and laterally homogeneous crustal structure of continental Asia, lateral changes in crustal thickness are dramatic along the Japanese Islands, particularly in the direction perpendicular across the width. The isodepth contours of the Moho depth in Figure 1 


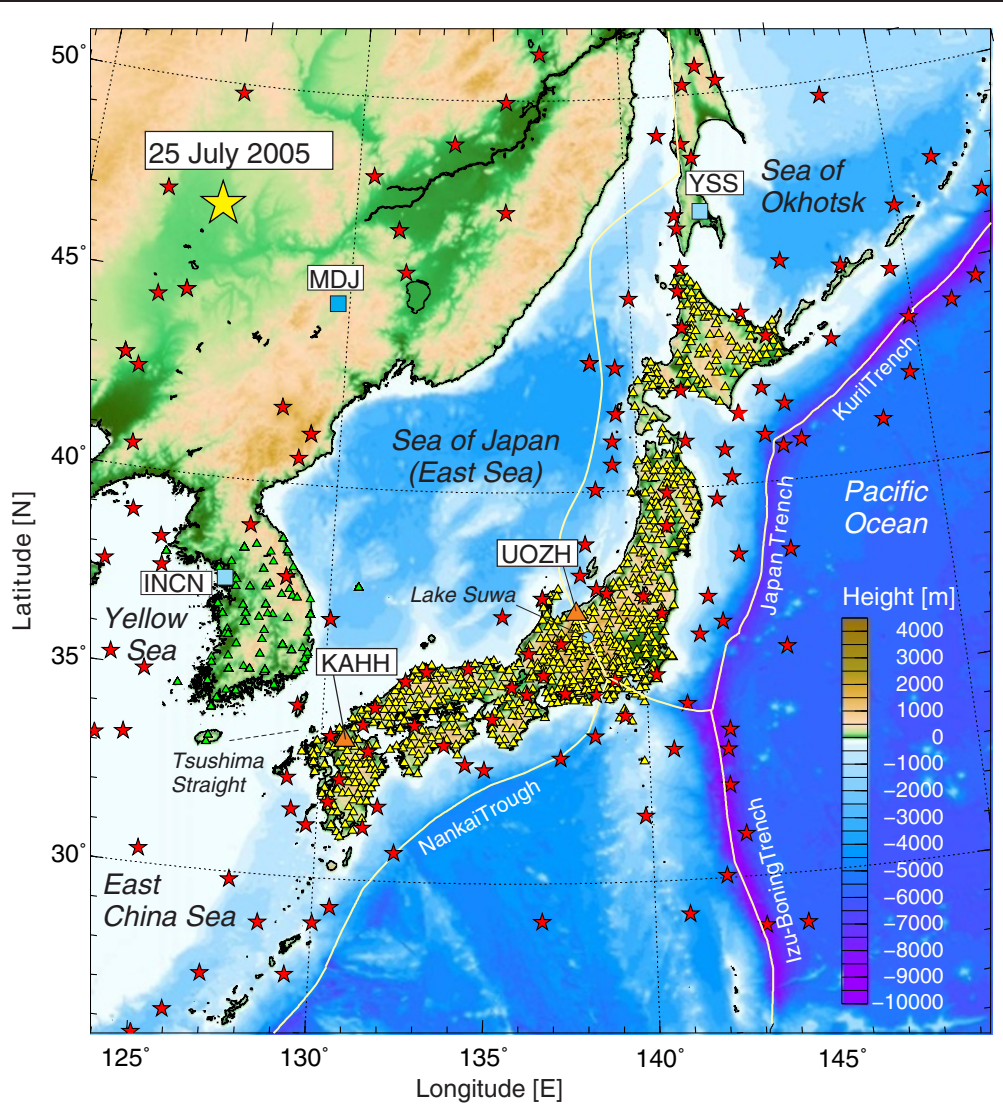

Figure 2 Distribution of seismic stations and earthquake epicenters used in this study. Map illustrating the stations in Hi-net in Japan (yellow triangles), the Korean network (green triangles), and Global Seismic Network (GSN) of the Incorporated Research Institutions for Seismology (IRIS) broadband stations (INCN, MDJ, YSS; blue squares) together with event epicenters (red stars) for the period from April 2001 to September 2013. The sea bottom topography is shown with a color scale.

display some deepened (>35 km) Moho depth zones in southern Hokkaido, Honshu, central Japan, and the area between Shikoku and Kyushu. Here, it can be seen that crustal thickness decreases rapidly with distance from the coast off the east and southwestern shorelines of the Japanese Islands towards the Pacific Ocean.

\section{Methods and Results}

\section{Waveform analysis}

Figure 2 shows the distribution of the Hi-net high-gain seismic network across Japan, which is operated by the National Research Institute for Earth Science and Disaster Prevention (NIED). This network consists of more than 800 stations with an average separation of approximately $20 \mathrm{~km}$. Each station consists of a three-component shortperiod $\left(f_{0}=1 \mathrm{~Hz}\right)$ velocimeter, and seismic data are continuously recorded at a sampling rate of $100 \mathrm{~Hz}$ (Okada et al. 2004; Obara et al. 2005). We also used the seismic stations the Global Seismic Network (GSN) of the Incorporated Research Institutions for Seismology (IRIS) in the study area, such as YSS in Sakhalin, MDJ in northeastern
China, and INCN in Korea, as well as short-period and broadband stations of the Korean seismological network operated by the Korea Institute of Geoscience and Mineral Resources (KIGAM) and the Korean Meteorological Administration (KMA) (Park et al. 2009) to improve the ray path coverage in this study area. The stations employed and the epicenters of the events studied are plotted in Figure 2.

Figure 3 shows examples of three-component seismograms of transverse $(\mathrm{T})$, radial $(\mathrm{R})$, and vertical $(\mathrm{Z})$ component ground motions recorded by the Hi-net stations. The upper panel (Figure 3a) shows the record of a Hi-net station in Honshu (UOZH; see Figure 2), and the lower panel (Figure 3b) shows the records of a shallow ( $h=12$ $\mathrm{km})$ intermediate scale ( $M w 5.0)$ earthquake that occurred in northeastern China on 25 July 2005 as recorded by a station in Kyushu (KAHH). The seismogram recorded by this station shows a clear $L g$ wave arrival as the largest signal on all three components, with a dominant frequency between 0.5 and $2 \mathrm{~Hz}$. The $L g$ wave also has an extended wave train spanning the group velocity range from 3.5 


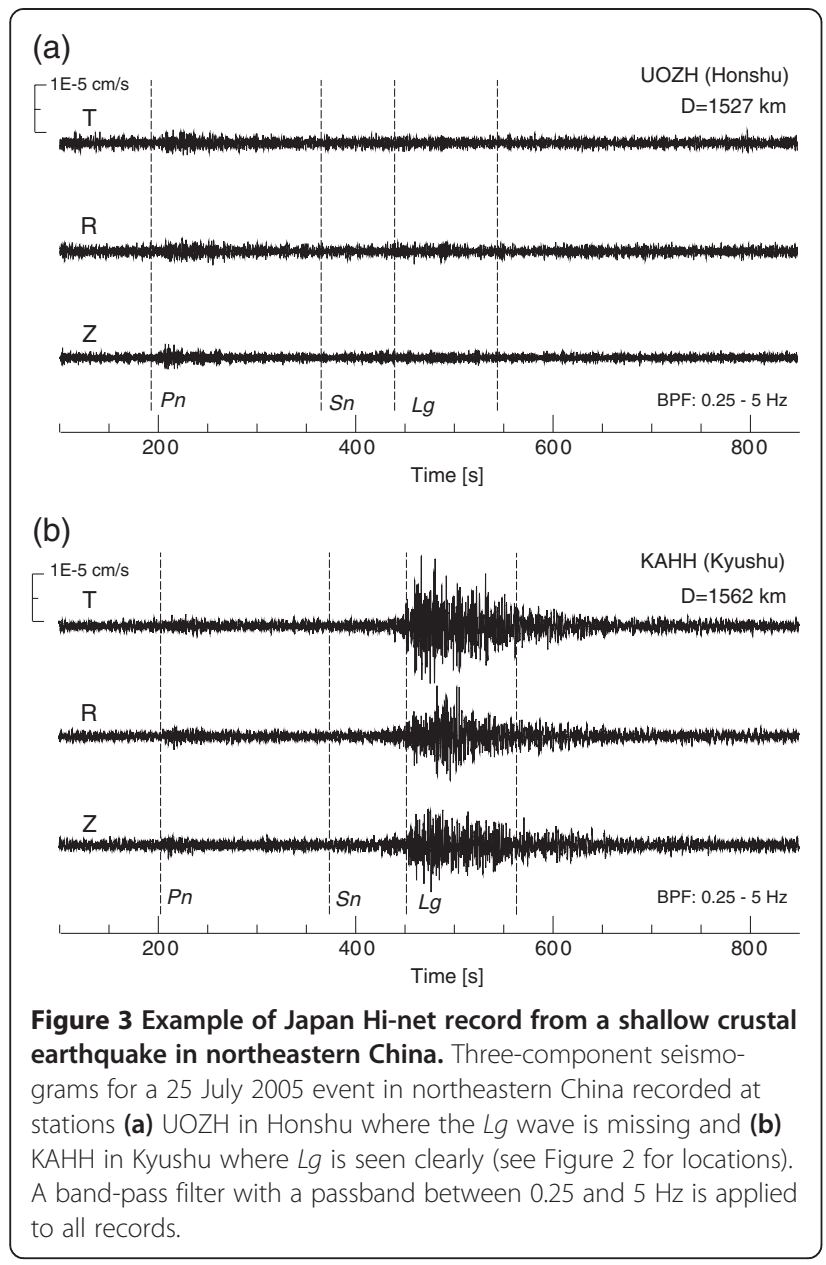

to $2.8 \mathrm{~km} / \mathrm{s}$ due to the superposition of multiple crustal-reflected shear waves. Thus, this $L g$ wave can be recognized as having developed from a superposition of multiple post-critical $S$ wave reflections propagating in the crust. Such clear $L g$ wave observations from a shallow $M w 5.0$ event traveling more than 1,500 km might seem rather surprising, but the same $L g$ wave is very difficult to see in the record of a Honshu station $(\mathrm{UOZH})$, which is at the same epicentral distance, even though the $P n$ phase amplitude is almost the same. These observations demonstrate the strong variation in both the crustal structure and nature of $L g$ wave propagation between continental Asia and Japan, through the Korean Peninsula, and across the Sea of Japan.

Usually, the mantle lid $S$ wave $(S n)$ phase is detected in the regional seismograms of shallow events, but it is not clearly seen in the seismograms of both the abovementioned stations. This is probably because of strong $S n$ wave attenuation during the long propagation of the lower Qs mantle structure in the back-arc side of tectonically active subduction zones.
Properties of the $L g$ waves around the Japanese Islands Figure 4 shows a vertical ( $\mathrm{Z}$ ) component of seismograms recorded by $30 \mathrm{Hi}$-net stations in Japan, which extend along the coast of the Sea of Japan from the north (Hokkaido) to the south (Kyushu) through Honshu. Here, we show the features of $L g$ wave propagation to Japan from three shallow events that occurred in (a) northeastern China, (b) the Yellow Sea, and (c) central Japan. The travel-time curves for the $\mathrm{Pn}, \mathrm{Sn}$, and $L g$ phases are shown on the record sections by assuming group velocities of $7.7 \mathrm{~km} / \mathrm{s}$ for $P n, 4.2 \mathrm{~km} / \mathrm{s}$ for $S n$, and 3.5 to $2.8 \mathrm{~km} / \mathrm{s}$ for the $L g$ phases, along with the later arrival for the $R g$ phase $(2.8 \mathrm{~km} / \mathrm{s})$. The amplitude of each trace is normalized by using the later $S$ wave coda (specifically, the coda normalization technique; Aki and Chouet 1975) in order to compensate for localized site amplification at each station. In this figure, we can see strong variations in the regional wavefield for the different events, especially for the efficiency and inefficiency of $L g$ wave propagation along the paths from the sources to the stations across different tectonic environments. For example, it can be seen that there is efficient $L g$ wave propagation along the path from continental Asia to Kyushu and Hokkaido, but $L g$ wave propagation is suppressed for paths across the Sea of Japan. Additionally, $L g$ wave propagation is very efficient in southwestern Japan, but much less effective in northeastern Japan, even though the mantle $P n$ phases for all three events could be clearly observed at most stations. Although the mantle $S n$ phase was clearly observed with propagation in western Japan (Figure 4c) and from the Korean Peninsula to Kyushu (Figure 4b), $S n$ phase attenuation was very strong in northern Japan and along the path across the Sea of Japan (Figure 4a).

We measured the efficiency of the $L g$ wave propagation along each path, from the sources to the monitoring stations, by taking the ratio of average $L g$ amplitude to average $S n$ amplitude in the group-velocity windows 4.6 to $4.2 \mathrm{~km} / \mathrm{s}$ for $S n$ and 3.5 to $2.8 \mathrm{~km} / \mathrm{s}$ for the $L g$ wave, and over the three components of the seismograms. In Figure 4, we show ray paths that have good $L g$ propagation paths $(L g / S n>1.5)$ in green and less efficient $(1.0<L g / S n<1.5)$ propagation paths in orange. The propagation paths with very weak or missing $L g(L g /$ $S n<1.0)$ are plotted in red. Note that in the area where the $S n$ wave is very small and comparable to the background noise level, the $L g / S n$ ratio measures the strength of the $L g$ wave relative to the noise occurring just prior to the $L g$ wave arrival.

We can immediately see that the $L g$ propagation is efficient along the paths from the Asian continent to Kyushu and Hokkaido that do not pass through the Sea of Japan. However, there is a sharp $L g$ wave signal cutoff in the record section of Figure 3a for stations in the east of Kyushu, even though the corresponding decline in $L g$ efficiency in 
(a) Northeastern China (25 July 2005)

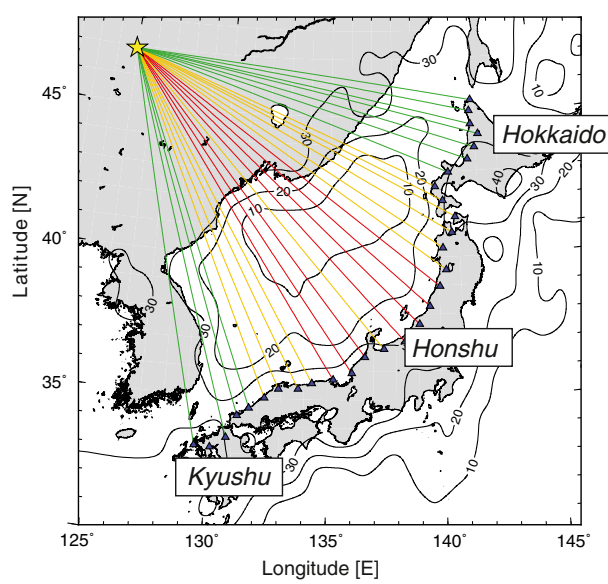

(b) Yellow Sea (22 March 2003)

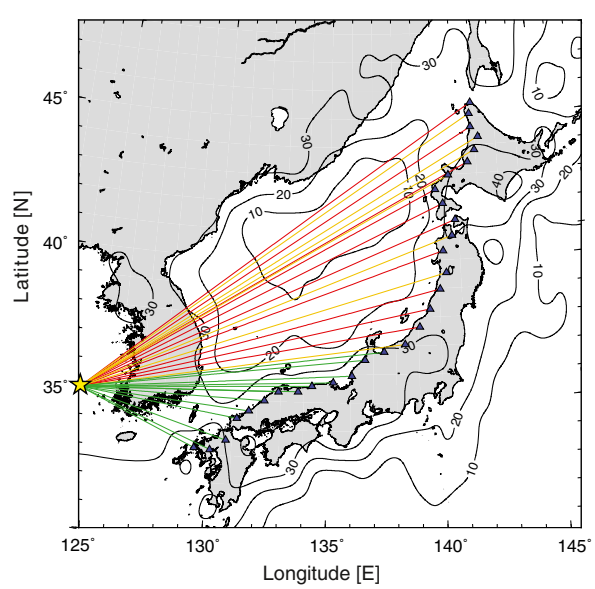

(c) Central Japan (30 September 2007)

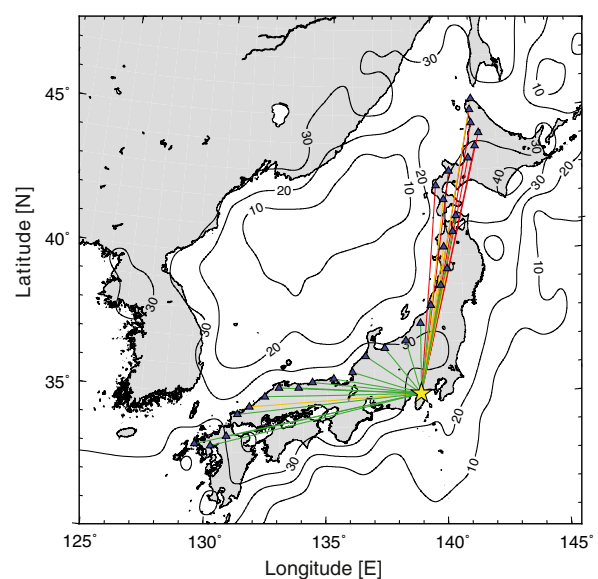

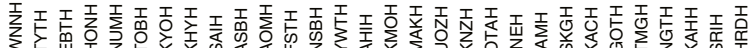

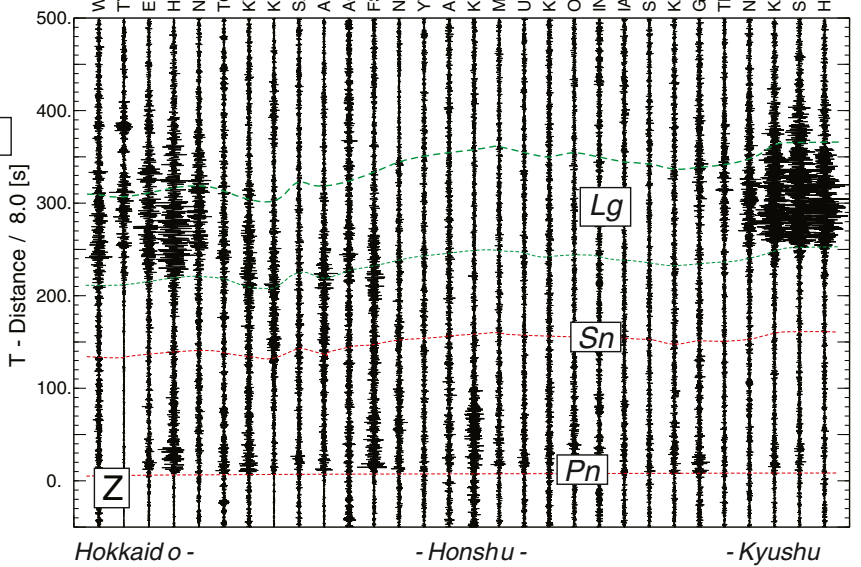

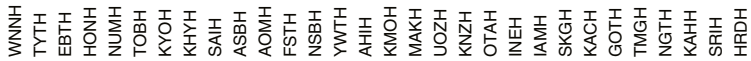

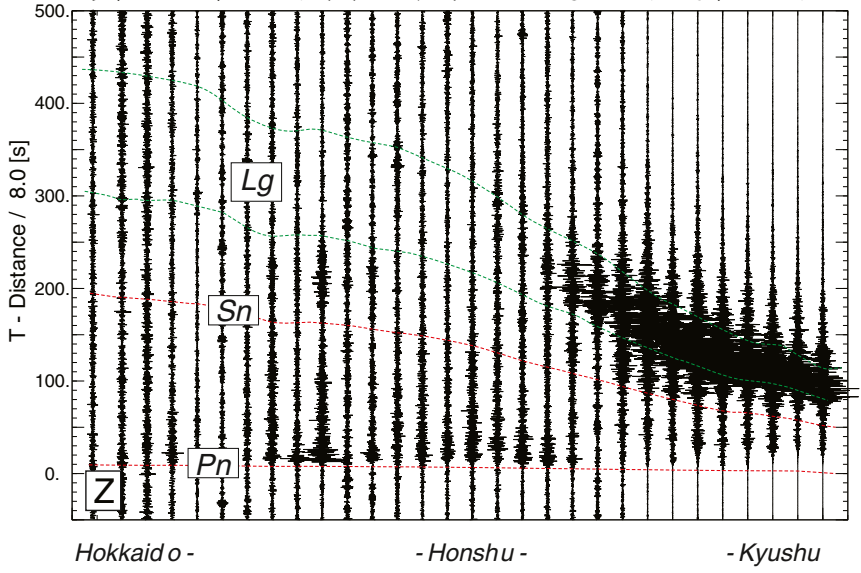

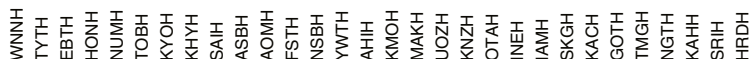

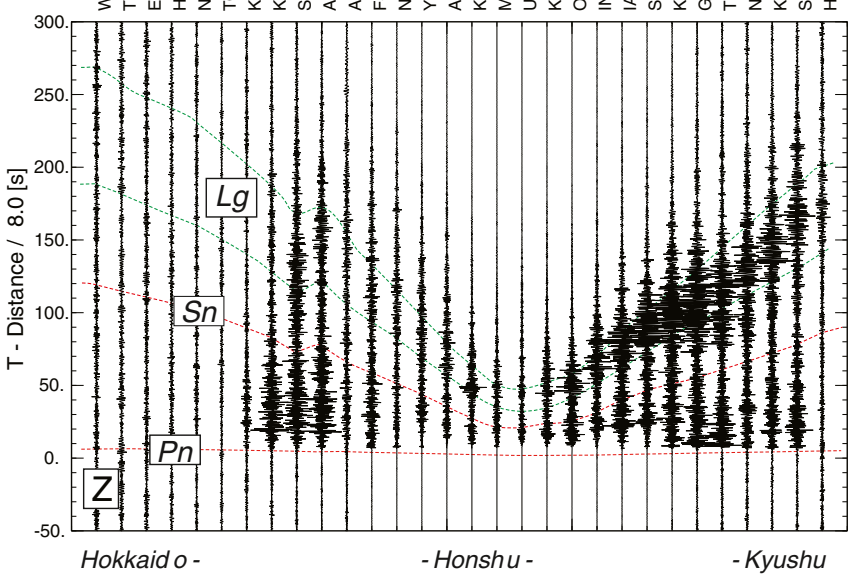

Figure $4 \mathrm{Lg}$ wave propagation from the Asian continent to Japan and along the Japanese Islands. Variation in the $L g / S n$ ratio along the paths from the event to recording stations and the corresponding vertical component seismograms recorded at Hi-net stations from Hokkaido to Kyushu. Isodepth contours of the Moho depth for 10, 20, 30, and $40 \mathrm{~km}$ are shown in the $L g$ propagation map. Efficient $L g$ paths (Lg/Sn>1.5) are shown in green, inefficient $L g(1.0<\mathrm{Lg} / \mathrm{S} n<1.5)$ are shown in orange, and no $\mathrm{Lg}(\mathrm{Lg} / \mathrm{S} n<1.0)$ shown in red. The frames display events in (a) northeastern China, (b) the Yellow Sea, and (c) central Japan. The travel times of Pn, Sn, and $L g$ are marked. The Hi-net station code is shown at the top of the seismogram sections. 
southern Hokkaido is not as drastic. This suggests that the transition from the continental to oceanic crustal structure along the northern margin of the Sea of Japan is not as sharp as that along the east close to the Korean Peninsula. Recent marine survey investigations involving refraction and reflection experiments have revealed that the crustal thickness beneath the northeastern side of the Sea of Japan (Japan Basin; see Figure 1) is roughly 10 to $12 \mathrm{~km}$ (Hirata et al. 1992), which is thicker than a typical ocean crust (about 5 to $7 \mathrm{~km}$ ) and that there is a large lateral crustal structure variation in the center of the Sea of Japan where the crustal thickness sudden grows to $22 \mathrm{~km}$ beneath the Yamato Bank (Kurashimo et al. 1996). The intermediate variations between the ocean and continent crustal structures beneath the Sea of Japan are associated with the lithospheric deformation that occurred during the opening of the sea, which resulted from continental rifting during the Oligocene and Miocene.

The efficient propagation of $L g$ waves across the Yellow Sea to Japan, which was first noted by Utsu (1958), is seen in Figure 4b. This observation is consistent with the continuity of continental Asia to the Korean Peninsula, the extension of the continental structure to the Yellow Sea, and to the north of the East China Sea.

In Japan, the $L g$ wave propagation is very clear in the western part of the country, but is not clearly seen from central to northern Honshu Japan, Hokkaido, and in southern Kyushu (Figure 4c), as pointed out by Furumura and Kennett (2001) and Kennett and Furumura (2001). These areas of inefficient $L g$ propagation correlate well to the zone of low- $Q$ anomaly in the crust (Nakamura and Uetake 2002; Sekine 2005). The $L g$ waves traveling to Hokkaido across the Pacific Ocean and the Sea of Japan for more than $100 \mathrm{~km}$ dissipate completely.

\section{Tomographic inversion of $L g$ propagation efficiency}

We chose 149 events in the area spanning $125^{\circ} \mathrm{E}$ to $145^{\circ} \mathrm{E}$ and $25^{\circ} \mathrm{N}$ to $55^{\circ} \mathrm{N}$, with source depths less than $33 \mathrm{~km}$ and magnitudes greater than $M w 4.5$ that occurred during the period between April 2001 and September 2013 (Figure 2). The coverage of 289,000 ray paths in total, from sources to stations, provides dense sampling over the study area. More than 500 of the ray paths sampled cross the Japanese Islands entirely, and more than 100 ray paths (covering most parts of the study area) travel across the Sea of Japan. However, relatively few ray paths $(<20)$ are found in the outer zone of the study area, such as in northeast China, the Yellow Sea, the East China Sea, the Sea of Okhotsk, and the eastern and southern Pacific Ocean. This might cause uncertainties when attempting to map $L g$ wave propagation properties in those outer areas (Figure 5).

We then applied a conventional tomography technique, following the procedure described by Furumura and Kennett (2001), in order to construct a detailed $L g$ propagation map across the study area. This tomographic inversion is based on the simultaneous iterative reconstruction technique (SIRT) such as that described by Kak and Slaney (1987) in their textbook, which was introduced for early medical computer tomography (CT) usage. Here, it is used to map the $L g / S n$ ratio value along a path with inversion for the local properties of the $\mathrm{Lg}$ wave transmission and blockage using $0.2^{\circ} \times 0.2^{\circ}$ cells. The iteration is repeated 10 times in situations where the assignment of $\mathrm{Lg} / \mathrm{Sn}$ ratio value to the cells along the ray path from the hypocenter to the station, and smoothing values in the neighboring eight cells are applied to stabilize the inversion result and create a smooth reconstruction image (see Furumura and Kennett (2001) for details). This SIRTbased inversion procedure has a modest conversion rate but works well with the large sparse system associated with $L g$ paths. Many other least-squares inversion approaches can be used, but those require a suitable damping procedure to stabilize the results.

We first assess the inversion resolution by looking for the reconstruction of a single-cell $\left(0.2^{\circ} \times 0.2^{\circ}\right)$ anomaly distributed across the study area on a $5^{\circ} \times 5^{\circ}$ grid. Figure 6 shows the results obtained from this point-spreading test, which indicates that even with the strong path coverage, there are possibilities for preferential anomaly smearing in certain directions. The source and station distribution offers fairly good coverage over the Japanese Islands from northeast to southwest, but there are fewer ray paths in the perpendicular direction. In consequence, there is a tendency for northeast-to-southwest resolution smearing to appear on the inversion map. For the same reason of abovementioned dominant ray path direction, there is a trend towards northwest-to-southeast smearing for $L g$ propagation anomalies on continental Asia. However, resolution in the Sea of Japan and in the Korean Peninsula is well controlled, with anomaly spreading recorded at less than $0.5^{\circ} \times 0.5^{\circ}$. In northeastern China, where ray path coverage is rather sparse (less than 200; see Figure 5), the point anomalies spread out to $1.5^{\circ} \times 1.5^{\circ}$.

The $L g$ propagation efficiency map results are shown in Figure 7 together with the crust thickness (the distance between surface/sea bottom and Moho), which provides a summary of the $L g$ wave propagation from continental Asia to Japan and around the Korean Peninsula. The green color on the map indicates areas where $L g$ wave propagation is efficient, and the red color indicates the least efficient $L g$ wave propagation area. Compared with the earlier study (Furumura and Kennett 2001), which employed data obtained from $J$-Array stations, the resolution of the present map, which uses the $\mathrm{Hi}$-net and Korean stations, represents a considerable improvement, and it can be seen that there is intense and almost uniform ray path coverage from continental Asia to Japan and across the Japanese Islands. Nevertheless, the $L g$ wave 


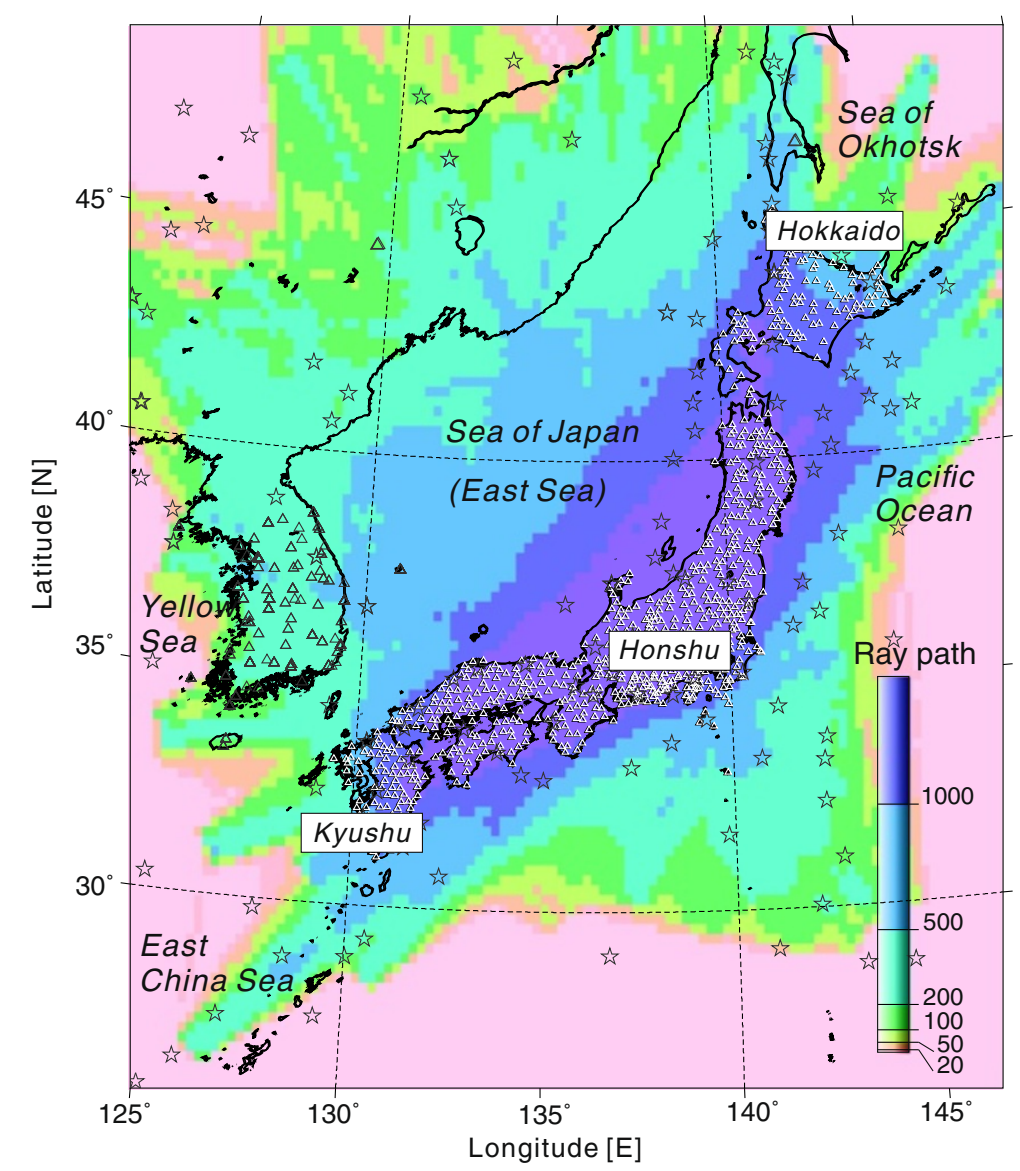

Figure 5 Ray density map of the study area. Map of ray path density counted in each $0.2^{\circ} \times 0.2^{\circ}$ cell showing the coverage and density of the ray paths in the study area. Source (squares) and stations (triangles) are shown.

propagation patterns shown are in good agreement with former studies (Furumura and Kennett 2001; Hong 2010) in their areas of coverage.

Also in Figure 7, we can see that the area of efficient $L g$ propagation continues from Asia to Kyushu through the Korean Peninsula across the Tsushima Strait and extends further west to the Yellow Sea and to the north of the East China Sea. In addition, an extension of relatively good $L g$ propagation is seen in the area from continental Asia to Hokkaido.

For the areas surrounding Japan, it can be seen that there is a sharp $L g$ wave propagation cutoff along the edge of the Sea of Japan where the crust thickness suddenly changes from a thick $(>30 \mathrm{~km})$ continental crust to a thinner $(<10 \mathrm{~km})$ oceanic crust (Kurashimo et al. 1996), and it has been confirmed that the $L g$ wave dissipation in the Sea of Japan starts when the crustal thickness decreases below $30 \mathrm{~km}$. The lighter red color in the northern half of the Sea of Japan indicates relatively weaker attenuation of the $L g$ wave than in the south, which is shown in dark red.

We also find that along the continent to oceanic boundary on the Pacific Ocean side of Japan (which corresponds roughly to the 1,000-m isodepth contour of the water depth), the $L g$ wave propagation is totally blocked. The darker red color in the Pacific Ocean indicates that the $L g$ attenuation across the Pacific Ocean is much stronger than that across the Sea of Japan.

On the west sides of the Japanese Islands, there is a good $L g$ propagation area that runs from central Honshu to northern Kyushu and then connects to continental Asia through the Korean Peninsula. In contrast, the $L g$ wave propagation is poor in northern Japan from central Honshu to southern Hokkaido, as well as in southern Kyushu. These findings are consistent with the earlier results of Furumura and Kennett (2001), and the area corresponds to the anomalously low $Q_{L g}(<200)$ zone derived in the inversion by Hong (2010).

Such areas of inefficient $L g$ wave propagation in Japan might relate to low- $Q$ anomalies in the crust beneath active volcanoes (shown as triangles in Figure 7), irregular topography at the surface and the Moho, and thick sediment cover. The net results of their effects are to disrupt coherent $L g$ reflection patterns in the crustal waveguide. 


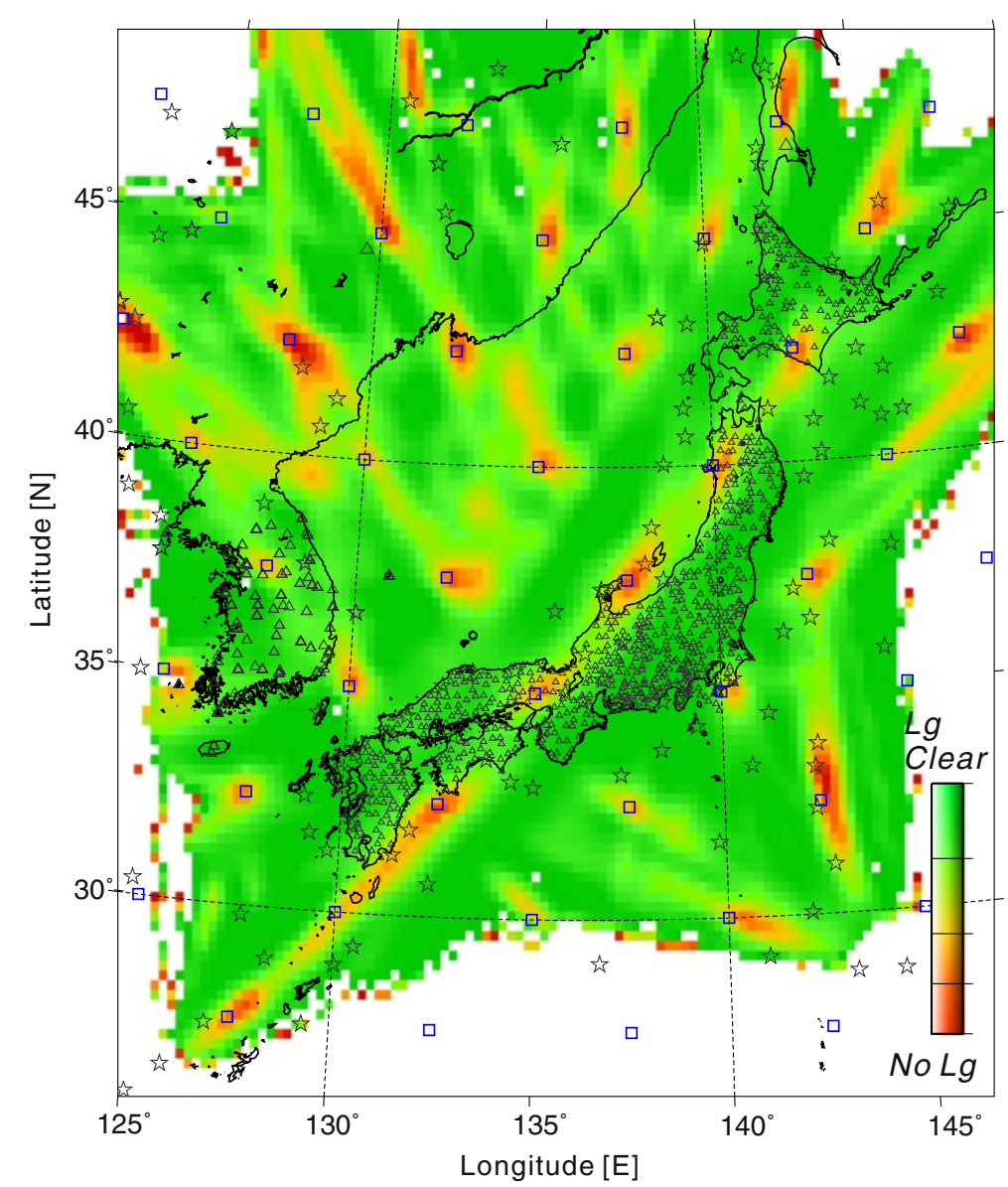

Figure 6 Resolution test for the inversion analysis of the $L g$ wave propagation. Resolution test for $L g$ wave propagation map shown in Figure 5 , illustrating the smearing pattern of the point $\left(0.2^{\circ} \times 0.2^{\circ}\right)$ anomalies placed at every $5^{\circ} \times 5^{\circ}$ (blue squares).

\section{Numerical investigation}

\section{Numerical simulation of $L g$ wave propagation}

In order to understand the processes by which an $L g$ wave is able to travel large distances (more than $1,000 \mathrm{~km}$ ) in the continental crustal waveguide, yet can be totally blocked by crustal barriers, we have produced a 3-D FDM simulation of seismic wave propagation in the study area using a heterogeneous crust and topography model based on the recently released CRUST 1.0 structural model (Laske et al. 2013). We then considered a wave propagation from the 25 July 2005 earthquake in northeastern China discussed in Figures 2, 3, 4a. The simulation area covers a horizontal zone of $1,900 \times$ $2,000 \mathrm{~km}$ and $96 \mathrm{~km}$ in depth, which has been discretized with a uniform grid size of $0.5 \mathrm{~km}$ in the horizontal direction and $0.25 \mathrm{~km}$ in the vertical direction (Figure 8). The heterogeneous crust and upper-mantle structure of the FDM simulation was constructed by assigning Lame's constants that relate to $P$ and $S$ wave speed ( $V p$ and $V s$, respectively), density $(r)$, and the anelastic attenuation constants for $P$ and $S$ waves ( $Q p$ and $Q s$, respectively) at each grid point of the 3-D simulation model. The seismic wave propagation at each grid point is calculated explicitly with increasing time steps and by solving the equation of motions using an eighth-order staggered-grid FDM in the horizontal directions and a fourth-order staggered-grid FDM in the vertical direction, where the smaller $(0.25 \mathrm{~km})$ grid is applied. The CRUST 1.0 structural model (Laske et al. 2013) provides depth distributions for topography, sedimentary layer, upper crust, middle crust, and lower crust, as well as the $P$ and $S$ wave speed and density at a resolution of $1^{\circ} \times 1^{\circ}$. The CRUST 1.0 model is expected to provide significant improvements over earlier crustal models in the area around the Sea of Japan, along the Japanese Islands (Ryoki 1999) and around the Korean Peninsula (Chang and Baag 2005) with the results of recent marine and land geophysical experiments. However, we did not adopt the sedimentary layer function of the CRUST 1.0 model since we had confirmed that the sediments in the study area were not uniformly covered by the present CRUST 1.0 model, but were instead restricted to those areas where marine experiments have 


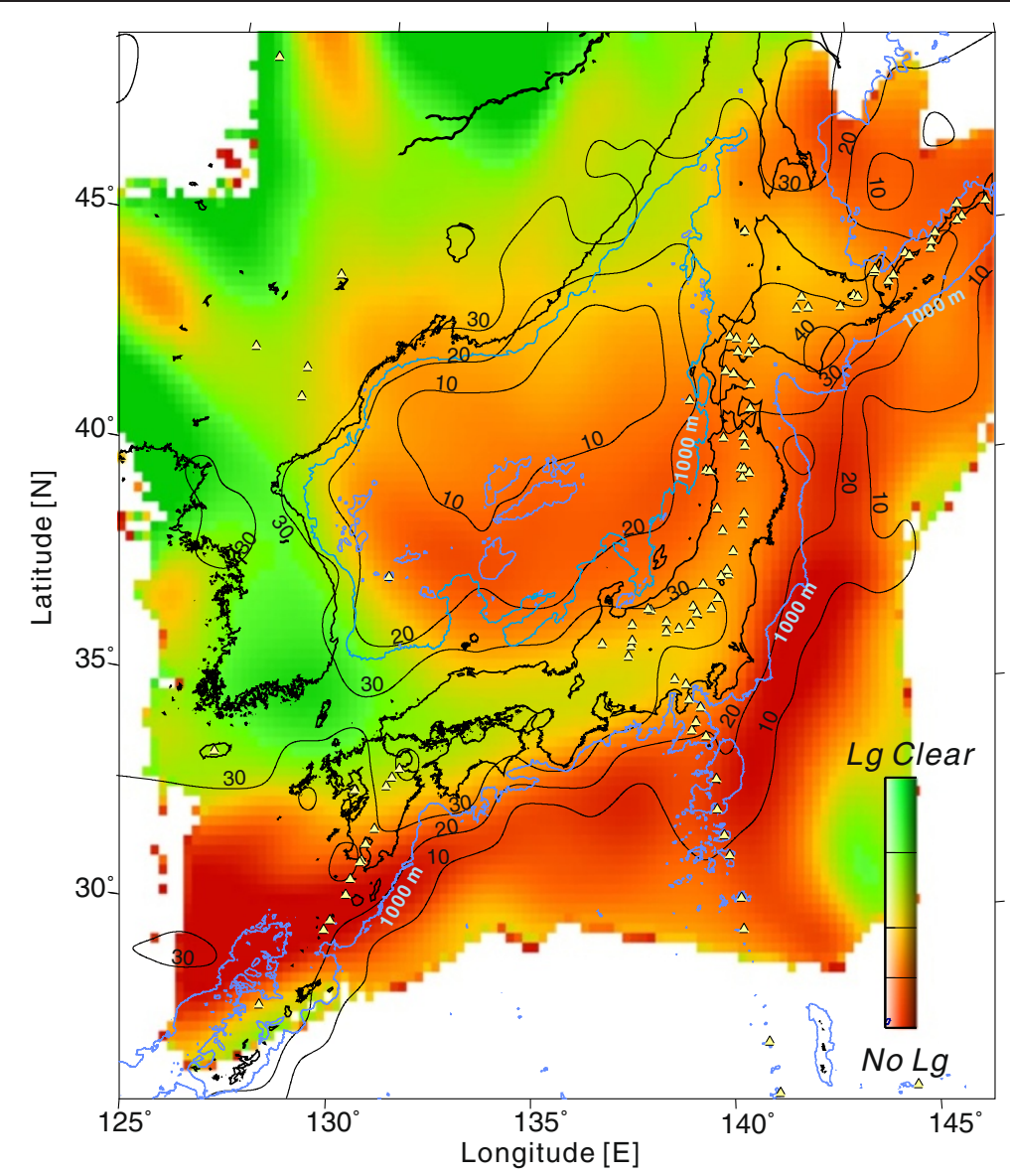

Figure $7 \mathrm{Lg}$ wave propagation map in the area around Japan. Summary map of the variation in the $L g$ wave propagation in the area around Japan derived from the inversion of the $L g / S n$ ratio. Green marks efficient $L g$ propagation, and red marks indicate inefficient $L g$ propagation. Triangles denote major active volcanoes. Black lines denote isodepth contours of the crustal thickness at 10-km intervals, and blue lines correspond to the 1,000-m contour of sea depth.

been carried out. Although low-wave speed and low- $Q$ sediments also have the potential to significantly effect $L g$ wave attenuation, the present simulation will only examine how changes in crustal thickness and sea depth affect $L g$ wave propagation.

The crustal model (Figure 8) shows strong lateral crustal structure changes with the crust thinning from a thick (30 to $35 \mathrm{~km}$ ) continental structure to a relatively thin (10- to 20-km-thick) oceanic structure along the outer boundary of the Sea of Japan, and a much thinner (5-to 10-km-thick) crust along the coastal edge of the Pacific Ocean. Along the Japanese Islands, a somewhat thicker crust (30 to $35 \mathrm{~km}$ ) extends from the northern island of Hokkaido to the southern island of Kyushu (with some bumps along the Moho) and then continues to the continental crust beneath the Yellow Sea, the northern part of East China Sea, and continental Asia, through the Korean Peninsula. There is some particularly noticeable Moho topography at the northeastern margin of the Sea of Japan between continental Asia and Hokkaido.
In the FDM simulation, the model has a minimum $P$ wave speed $(V p=1.5 \mathrm{~km} / \mathrm{s})$ in seawater and a minimum $S$ wave speed $(V s=3.5 \mathrm{~km} / \mathrm{s})$ in the upper crust, which allows for $S$ wave propagation simulations at frequencies less than $1.5 \mathrm{~Hz}$, with a sampling rate of 3.5 grid points per minimum $S$ wavelength.

Since the CRUST 1.0 structural model was believed to be too simple to represent the scattering of highfrequency waves, which play an important role in shaping the character of high-frequency seismic signals above 0.5 to $1 \mathrm{~Hz}$, we superimposed stochastic random heterogeneity to deviate $P$ and $S$ speeds of the CRUST 1.0 model of the crust and upper-mantle. We used a von Karman stochastic random heterogeneity distribution function with a longer horizontally correlation distance $\left(a_{x}=10 \mathrm{~km}\right)$ than vertical $\left(a_{z}=0.5 \mathrm{~km}\right)$ and a $2 \%$ standard deviation of $P$ and $S$ wave speeds. In the upper mantle, we use a somewhat larger scale of heterogeneity ( $a_{x}=20 \mathrm{~km}, a_{z}=1 \mathrm{~km}$, and $2 \%$ standard deviation) than that in the crust. 


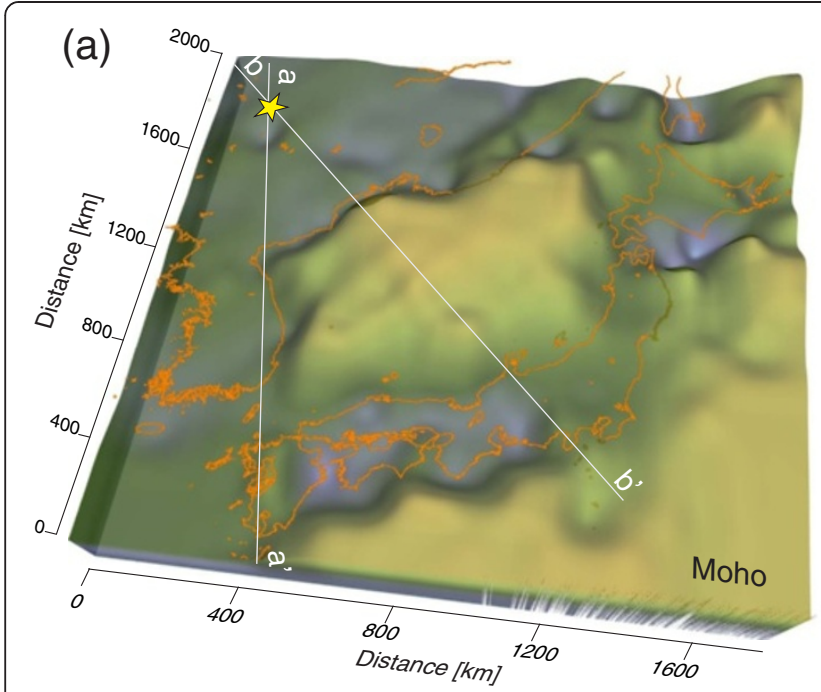

(b)

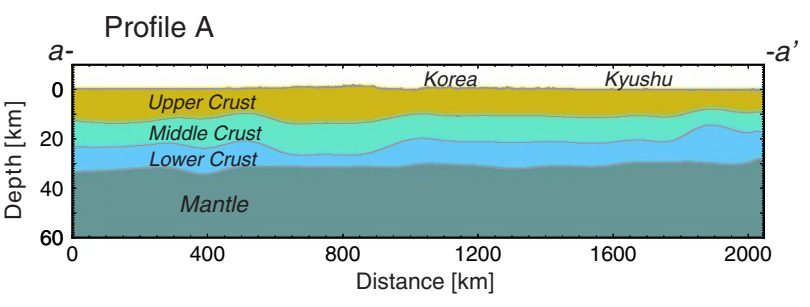

Figure 8 3-D model of crustal structure used in the FDM simulations. (a) 3-D view of Moho depth. (b) Vertical profiles of crustal structure along profile $\mathrm{A}$ and profile $\mathrm{B}$ showing lateral crustal structure variations.

Anelastic attenuation for both $Q p$ and $Q s$ is employed in the FDM simulation using the frequency-independent $Q$ model implemented for the FDM simulation created by Robertsson et al. (1994). After some preliminary experiments, we finally selected the anelastic parameters of $Q s=400$ for the crust and $Q s=350$ for the mantle, with $Q p=2 \times Q s$ calculated by comparing the relative strength of the $P n, S n$, and $L g$ phases in the observed seismograms. The relatively low Qs (equal to 350 to 400 ) compared with that of the normal value (e.g., $Q s=1,000)$ in the continental structure might correspond to the low- $Q$ mantle lid below the Sea of Japan. The lower Qs in the crust and mantle are consistent with those of the Japan Seismic Hazard Information Station (J-SHIS) standard velocity model (Azuma et al. 2013) corresponding to the tectonics of the young and tectonically active Japanese Islands. We assigned a large $Q p$ (equal to 10,000) for seawater.

Following the Harvard centroid moment tensor (CMT) catalog solution (Harvard Seismology Group, Cambridge, MA, USA), a double-couple reverse-fault point source for the 25 July 2005 northeastern China earthquake (see Figure 4a) is placed in the upper left of the simulation model at a depth of $12 \mathrm{~km}$. This source radiates seismic wave into the crust with a maximum frequency of $f=1.5 \mathrm{~Hz}$.

The 3-D FDM simulation was conducted on the Earth Simulator supercomputer (Earth Simulator Center) while employing 1.02 TByte of memory for a single-precision calculation with a wall-clock time of $6.5 \mathrm{~h}$ using 32 supercomputer nodes (256 vector processors) and 50,000 time steps in order to carry wave propagation out to $750 \mathrm{~s}$ after initiation. Snapshots of seismic wave propagation derived from the FDM simulation for the northeastern China earthquake that display the way in which the regional wavefield spreads from a shallow source in the continent are shown in
Figure 9. The simulated wavefield is separated into the $P$ wave contribution by taking the divergence of the 3-D wavefield plotted in red, and the $S$ wave contribution is plotted by extracting the curl (rot.) of the 3-D wavefield shown in green. The wave amplitudes in the snapshot are multiplied by the hypocentral distance to each grid point in order to compensate for the geometrical attenuation of the body waves and to improve the visibility of the seismic phases in the later timeframes.

In the first frame of the snapshot taken $180 \mathrm{~s}$ after the earthquake initiation (Figure 9a), the spreading of the $P$ and $S$ waves from the source shows an isotropic distribution. The original radiation pattern of the $P$ and $S$ waves is largely eliminated by multiple reflections and scattering in the heterogeneous subsurface structure. As time passes, the $L g$ wave builds up as a sequence of multiple postcritical $S$ wave reflections in the crust, which then appear in the snapshot along with a spread of $S$ wave energy over continental Asia for more than $400 \mathrm{~km}$.

For the $P g$ wave, which is a sum of multiple wide-angle $P$ wave reflections in the crust (somewhat like the $L g$ wave for $S$ ), the attenuation is rather strong and difficult to see in the next $(T=280 \mathrm{~s})$ time frame of the snapshots. This is because the $P$ wave reflection is not totally occurred when the $P$ waves encounter the free surface and Moho, so some of the $P$ wave energy is successively transmitted to the mantle by $P g$-to- $S$ conversion when bouncing from the Moho.

As the $L g$ wave emerges from continental Asia and propagates into the Sea of Japan, its progression suddenly attenuates along the thinner crust (Figure 9c; $T=380 \mathrm{~s}$ ). Following the continental to oceanic transition, the circular wavefront of the $L g$ wave cuts sharply along the eastern coast of Korean Peninsula and between the Asian 


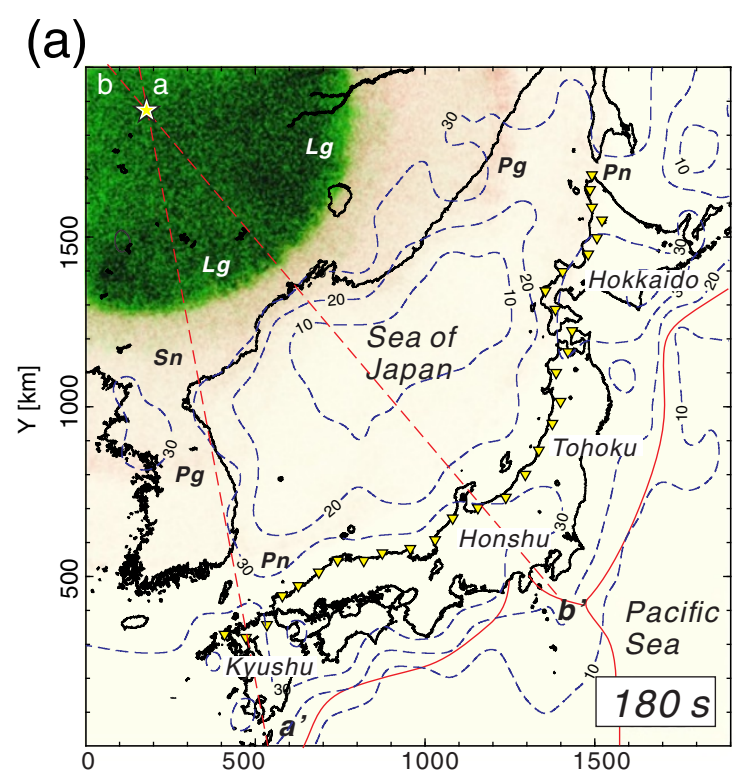

(c)

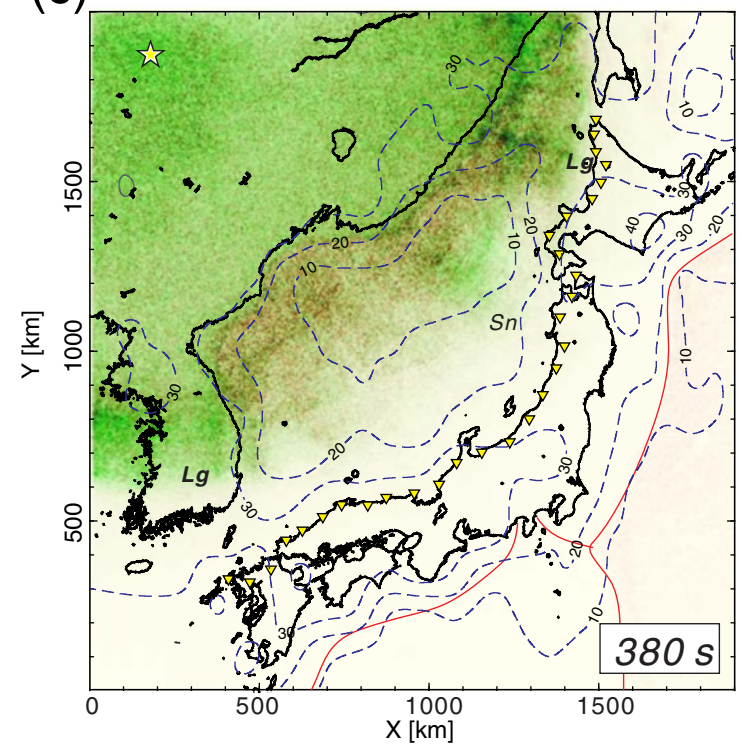

(b)

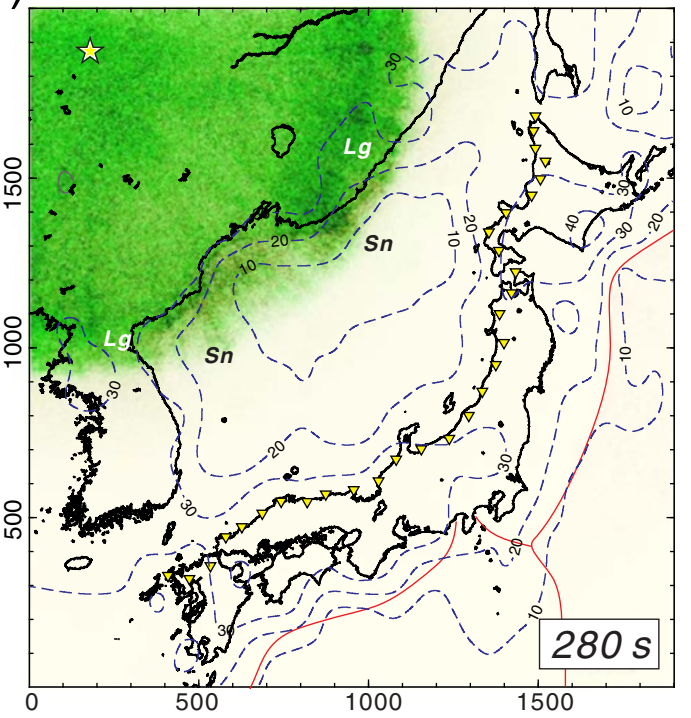

(d)

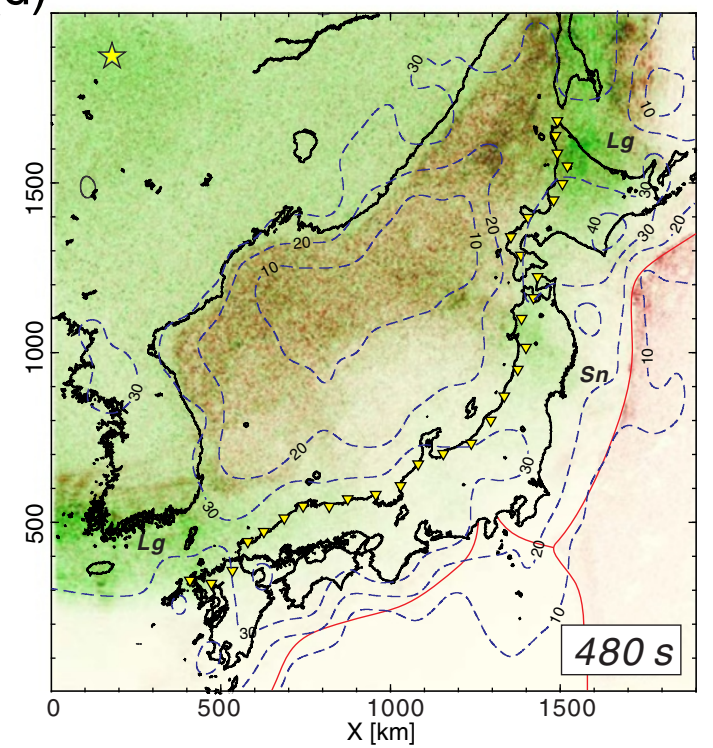

Figure 9 Snapshots of seismic wavefield for surface ground motion derived from the 3-D FDM simulation. Snapshots of the seismic wavefield of the surface ground motion at time $T=180 \mathrm{~s}$ (a), $280 \mathrm{~s}$ (b), $380 \mathrm{~s}$ (c), and $480 \mathrm{~s}$ (d) from the earthquake start. $P$ waves are shown in red, and $\mathrm{S}$ waves are shown in green. Isodepth contours of the crustal thickness are shown by purple lines. Red lines denote plate boundaries. Major phases are marked.

continent and Hokkaido (between the Eurasian and North American plates). We conjecture that the transmission of $L g$ wave energy into the mantle from the slope of the thinning crustal boundary and that multiple reflections of the $L g$ wave within the thinner crust of irregular seafloor and Moho boundaries cause the $L g$ wave to attenuate rapidly. The spread of red color ( $P$ wave) across the Sea of Japan with a long duration in the sea indicates that $L g$-to- $P$ conversion has occurred at the crust-sea interface, which also removes seismic energy from the $L g$ wave in the thinner crust.
Since Press and Ewing (1952), it has been recognized that anything more than $100 \mathrm{~km}$ of propagation along a purely oceanic path is sufficient to totally eliminate an $L g$ wave. Observations of weak $L g$ waves crossing 300 $\mathrm{km}$ of the middle of the Sea of Japan occur because the crust is much thicker (10 to $20 \mathrm{~km}$ ) than a normal ocean crust $(7 \mathrm{~km})$.

The last frame of the snapshot $(T=480 \mathrm{~s})$ illustrates the remainder of the $L g$ wavefront traveling in northern Hokkaido and arriving in western Kyushu with a long tail. This confirms our observations of efficient $L g$ wave 
propagation from continental Asia to Japan (with a propagation distance of more than $1,500 \mathrm{~km}$ ) and inefficient propagation to Honshu across the Sea of Japan. There is also a pronounced area extending through Honshu from central Japan to the northern Tohoku region in which the $L g$ wave propagation is inefficient.

A segment of the $S$ wave signal with a long coda can be found in northern Honshu (Tohoku) in the last frame ( $T=480 \mathrm{~s}$ ). This was developed by strong $S$ wave focusing along the concave crustal structure at the northwestern margin of the Sea of Japan and propagation in the mantle as an $S n$ wave to the Tohoku region.

In Figure 10, synthetic seismograms of the verticalcomponent ground velocity from the simulation are compared with Hi-net record observations for the northeastern China event, along with the application of a band-pass filter with corners at 0.5 to $1.5 \mathrm{~Hz}$. In the simulation, we can see the arrival of a clear $L g$ wave train in Kyushu and Hokkaido,

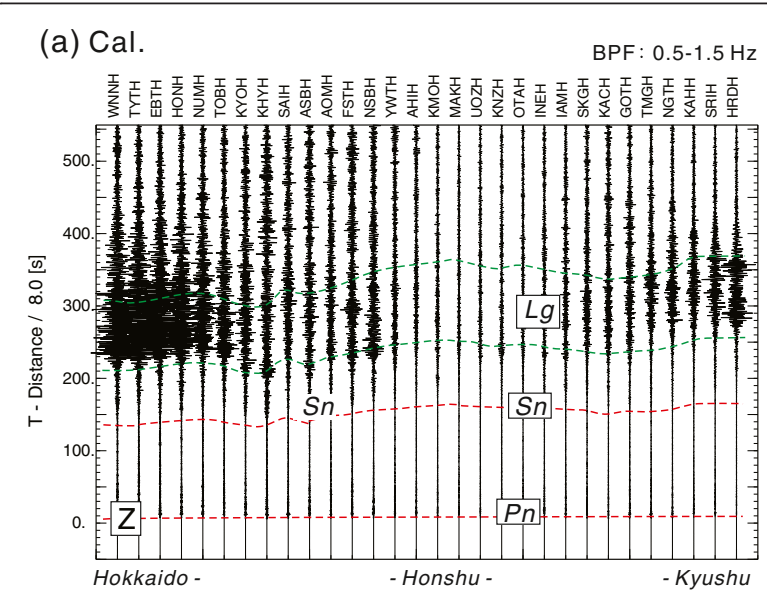

(b). Obs. BPF : $0.5-1.5 \mathrm{~Hz}$

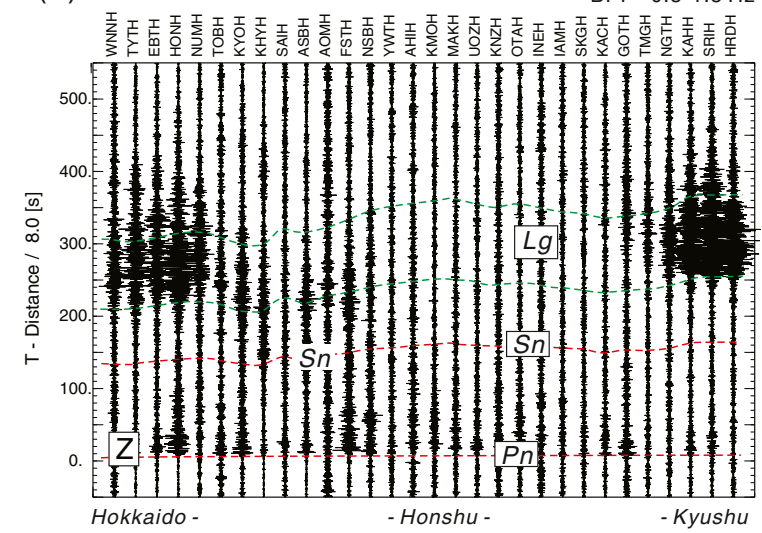

Figure 10 Record sections derived by the 3-D FDM simulation and $\mathrm{Hi}$-net observations. Comparison of record sections of verticalcomponent ground motion for station from Hokkaido (left) to Kyushu for (a) synthetic seismogram derived by the FDM simulation and (b) observed seismograms at Hi-net stations. A band-pass filter with a pass band frequency between 0.5 and $1.5 \mathrm{~Hz}$ is applied to both records to facilitate comparison. but no $L g$ wave can be seen in the Honshu stations, just as we have seen in the Hi-net data. However, the amplitude of the simulated $L g$ wave in Kyushu is relatively small when compared with the actual observation. We tried to solve this problem by taking into consideration uncertainties in the estimated focal mechanism and depth of the source which might modifying slightly the $S$ wave radiation pattern, but the relative weakness of the $L g$ wave in Kyushu did not show significant improvement. We believe that the problems arise from subtle issues in the structural model, such as the delicate curvature of the Moho along the continental to oceanic boundary.

A larger $S n$ wave with a long coda that was developed by $L g$-to- $S n$ wave conversion, which results from the strong focusing and defocusing effect imposed by the irregular Moho interface and heterogeneous crustal structures, is seen in the snapshots (Figure 9c,d). This wave appears across numerous stations between Hokkaido and Tohoku within the time window expected for the $S n$ and $L g$ waves. These long-tailed converted $S n$ waves are more clearly seen in the high-frequency seismograms of the Hi-net (see Figure 4a) in Hokkaido (e.g., KHYH) and in the Tohoku region (e.g., ASBH).

The present FDM simulation results obtained using the CRUST 1.0 model well explain the broad features of the observed regional wavefields that develop in continental Asia and travel to Japan across the Sea of Japan. However, further refinement of the simulation model is likely to be necessary in order to match the observations more consistently. For example, it would appear that there are problems with our understanding of the continent-ocean transition because the continental margin off the east coast of the Korean Peninsula appears to be too sharp and cuts out $L g$ energy that should arrive in Kyushu (snapshot Figure 9d). On the other hand, the transition at the northeast margin of the Sea of Japan may need to be sharper than in the current model in order to match the rapid drop in $L g$ amplitude seen in southern Hokkaido.

\section{Features of regional phases}

In order to show how $L g$ wave propagation patterns are drastically modified by interaction with crustal heterogeneities and can be totally blocked by crustal barriers such as the central Sea of Japan, we show a set of snapshots in a vertical section by cutting the FDM model along a profile from the source to a station, together with a record section of synthetic seismograms along the profile.

Figure 11 shows a snapshot of the seismic wavefield along the profile from continental Asia to Kyushu (where the $L g$ propagation is very efficient) together with synthetic seismograms of vertical-component ground motions along the profile (profile A; see Figures 8a,b and 9c). Each seismogram trace is multiplied by the epicentral distance in order 


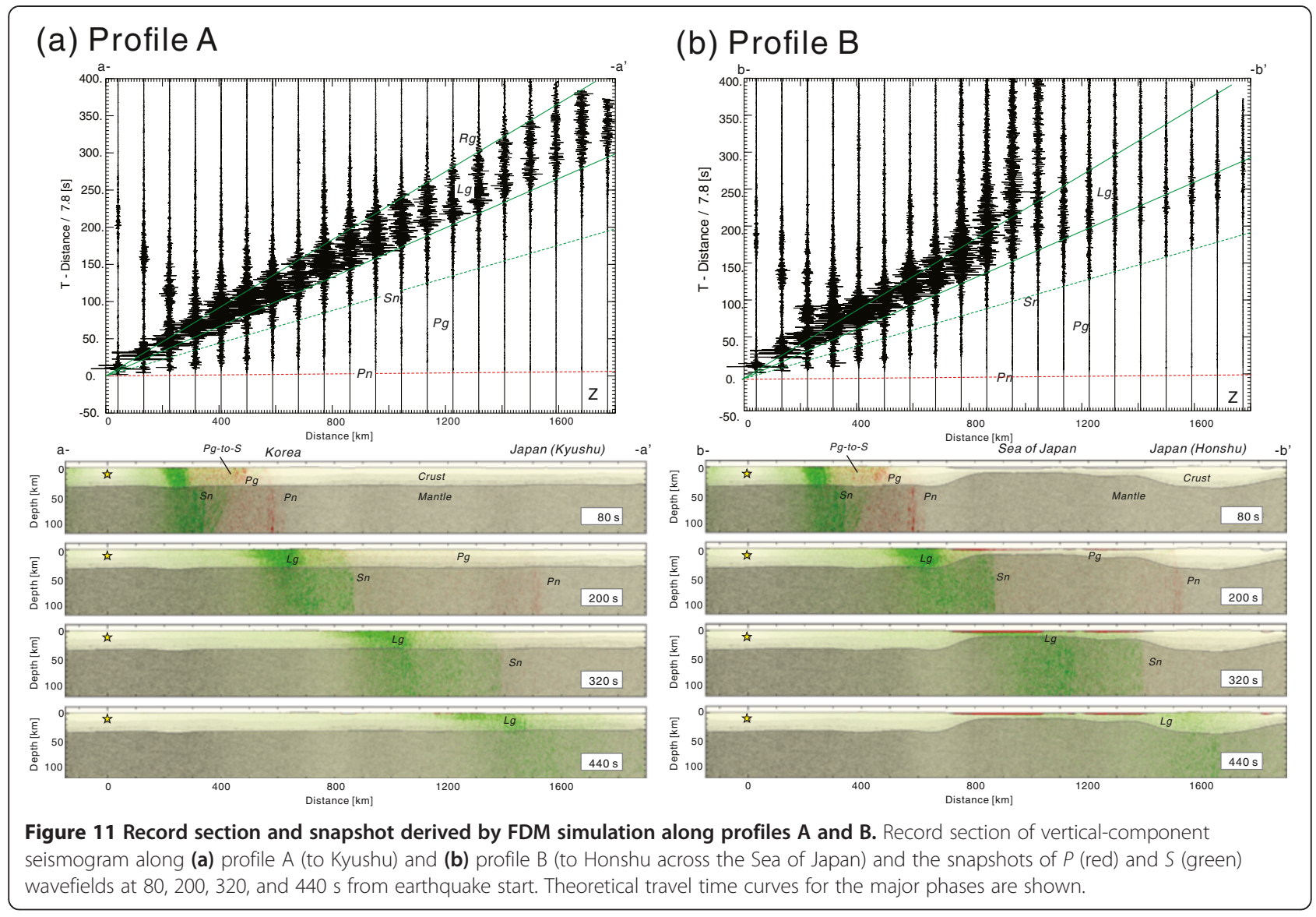

to compensate for the geometrical spreading of body waves.

The first frame of the snapshot ( $T=80 \mathrm{~s}$ ) displays the $L g$ wave train build up resulting from multiple post-critical $S$ wave reflections between the free surface and Moho. As can be seen in the figure, $L g$ wave propagation is very efficient in the continental structure, which is able to carry $S$ wave energy over distances in excess of $1,500 \mathrm{~km}$. The multiple forward scattering of the high-frequency waves in the crust from the horizontally elongated configuration of the small-scale heterogeneities also helps trap high-frequency $(f>1 \mathrm{~Hz}) L g$ wave energy in the crustal waveguide. In the second frame of the snapshot $(T=200 \mathrm{~s})$, the $S n$ wave separates from the $L g$ wave due to a faster $S$ wave speed in the mantle.

A weak $P n$ wave can be found propagating in the crust and mantle as a head wave while keeping nearly the same amplitude in all frames. The attenuation of the $P g$ phase propagating in the crust is very strong because large $P g$-to- $S$ conversion occurs at the free surface and the Moho (shown in green between $P g$ and $S n$ in the $T=80$ and 200-s frames), which removes the $P g$ wave energy from the crust down to the mantle. In the $T=200$-s time frame, it is hard to see the $P g$ wave signal. It is also recognized that the $P g$ wave often develops with a low-wave speed layer cover below the surface (see Olsen et al. 1983), but it might be underestimated in the present simulation where no sedimentary layer is present. The record section of the vertical-component ground motion along the path from the Asian continent to Kyushu along the Korean Peninsula illustrates the band of $L g$ waves developed by a superposition of the $S$ wave reflections in the crust, which leads to an extended wave train with a group velocity range 3.5 to $2.8 \mathrm{~km} / \mathrm{s}$. Some $L g$ wave attenuation occurs beyond 1,300 km when the waves cross the sea between Korea and Kyushu.

\section{Lg crustal barrier blockage}

We will now look at the process by which the crustal barrier beneath the Sea of Japan blocks the $L g$ wave propagation. In Figure 11b, we show snapshots of a vertical section of the simulated seismic wavefield, in addition to synthetic seismograms along the profile from continental Asia to Honshu across the Sea of Japan (profile B; see Figures 8a,b and 9c).

These snapshots demonstrate the process by which the sudden upheaval of the Moho from 35 to $10 \mathrm{~km}$ at the continental to oceanic margin (over a distance of $100 \mathrm{~km}$ ) and the extension of the thinner (10 km thick) crust over $600 \mathrm{~km}$ blocks the $L g$ wave propagation. This 
blockage occurs primarily by transferring the $L g$ wave energy into the mantle as a consequence of the rising Moho slope (see the $T=200$ - and 320-s frames), but the multiple $L g$ wave reflections in the thinner crust between the sea bottom and at the rough topography of the Moho top also leads to a dramatic decline of the $L g$ wave energy in the waveguide. In addition, significant $L g$-to- $P$ conversion occurs at the sea bottom due to the multiple reflections in the thinner crust, which also leads to a larger removal of $L g$ wave energy from the waveguide (see the red color in the sea in $T=320$-s frame). The transmitted $S$ wave propagates in the mantle as an $S n$ wave with a faster speed, and some of this energy is returned to the crust when the $S n$ waves impinge on the thick continental structure beneath Honshu (see the $T=440-\mathrm{s}$ frame). This converted $S n$-to- $L g$ energy arrives earlier than would be expected for the $L g$ wave itself. Some $L g$ wave energy dissipates into the water of the Sea of Japan due to $L g$-to- $P$ conversion at the sea bottom, and some of this energy can also be transferred to the crustal waveguide at a later time and results in the development of a long $L g$ wave coda. The overall attenuation of the $L g$ wave is very significant because of its interaction with the crustal barrier, which results in a sudden thinning of the crustal waveguide from 35 to $10 \mathrm{~km}$ over a distance of $100 \mathrm{~km}$, and due to the more than $600 \mathrm{~km}$ extent of a thinner $(10 \mathrm{~km})$ waveguide, which results in $L g$ wave energy dissipation into the seawater by $L g$-to- $P$ conversion. Consequently, very weak $L g$ waves can be seen in the right corner of the snapshot in the last $(T=440 \mathrm{~s})$ time frame.

The synthetic seismograms of the vertical ground motion component along the profile across the crustal barrier demonstrate the dramatic attenuation of the $L g$ wave energy as it crosses the Sea of Japan over a 1,400$\mathrm{km}$ distance from the hypocenter onwards. The loss of the $L g$ wave energy as it propagates across the crustal barrier is significantly enhanced when compared with that of an $L g$ wave propagating in a predominantly continental environment (Figure 11a). The long tail of the $L g$ coda is the result of $P$-to- $L g$ conversions at the sea bottom and is caused by multiple $P$ wave reverberations in the seawater, as we observed in the seismic wavefield snapshots. We also note an enhancement of the $S n$ wave and its coda at points above the crustal barrier $(1,100 \mathrm{~km}$ from the hypocenter) as $L g$ wave energy is transmitted into the mantle.

\section{Lg attenuation}

In Figure 12, we compare the apparent attenuation of $L g$ waves along paths crossing the continental crust (profile A) and across the Sea of Japan (profile B) as a function of epicentral distance. To accomplish this, we measure the averaged root-mean-square (RMS) amplitude of the $L g$

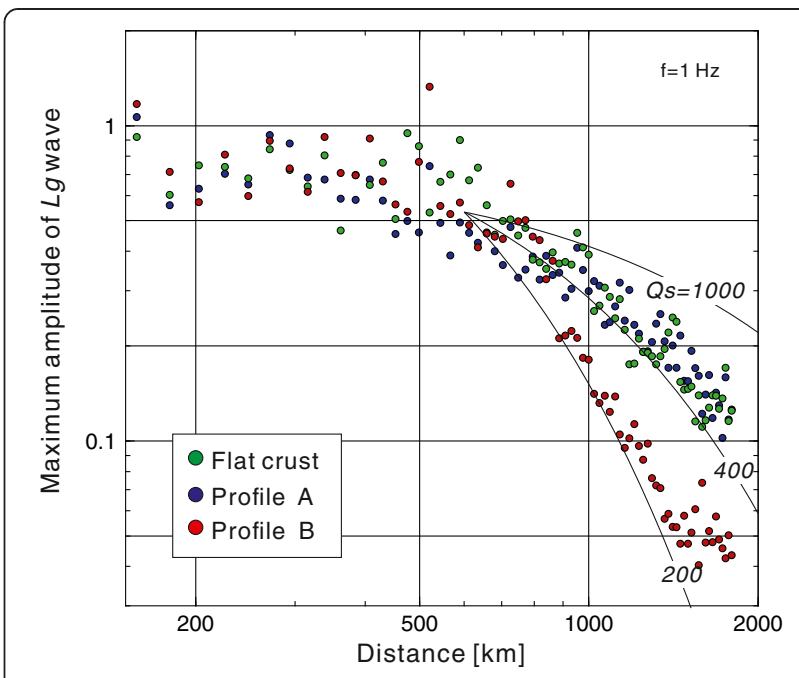

Figure 12 Attenuation functions of $L g$ wave along profiles $A$ and $\mathbf{B}$. Comparison of the attenuation functions of the maximum amplitude of the $\mathrm{L} g$ wave of $1 \mathrm{~Hz}$ for the synthetic seismogram derived from the FDM simulation as a function of distance from the hypocenter along profile A (blue circles) and along profile B (red circles). The attenuation function for a laterally homogeneous flatcrust model is also shown (green circles). The theoretical attenuation curves for the $L g$ wave in anelastic media ( $Q s=1000,400$, and 200) is also displayed by solid lines.

wave on the seismograms for frequencies around $1 \mathrm{~Hz}$ by applying a band-pass filter with a pass band frequency between 0.75 and $1.5 \mathrm{~Hz}$. We also examine $L g$ wave attenuation based on an FDM simulation using a uniform $35-\mathrm{km}$-thick crust (flat-crust model) as a reference. Figure 12 plots the RMS amplitude of the $L g$ wave for the models of profiles A and B with the theoretical attenuation functions of the $L g$ wave, assuming the anelastic coefficients of $Q s=200,400$, and 1,000 and the geometrical spreading factor of the $L g$ wave $\left(r^{-0.83}\right.$, where $r$ is the hypocentral distance) (Nuttli 1973).

The apparent attenuation of the $L g$ waves for the profile A model is comparable to that for the flat-crust model with a laterally homogeneous crustal structure and fits the theoretical attenuation function with $Q s=400$, which is the value assigned to the crust in the present FDM simulation. For the laterally heterogeneous waveguide of the profile B model, the $L g$ wave attenuation is very strong and tends to follow the apparent attenuation function for $Q s=200$ and geometrical spreading factor of $r^{-0.83}$.

It is obvious that such drastic $L g$ wave attenuation results from an increase in the effective geometrical spreading factor associated with the laterally heterogeneous and thinner crustal waveguide, rather than a decrease of the Qs value in the crust. We note that the seismic waves lose amplitude with propagation due to spreading of seismic wave energy (geometrical spreading effect), which, for body waves, are often represented as $r^{-1}$ (and $r^{-0.83}$ for $L g$ wave), where $r$ is 


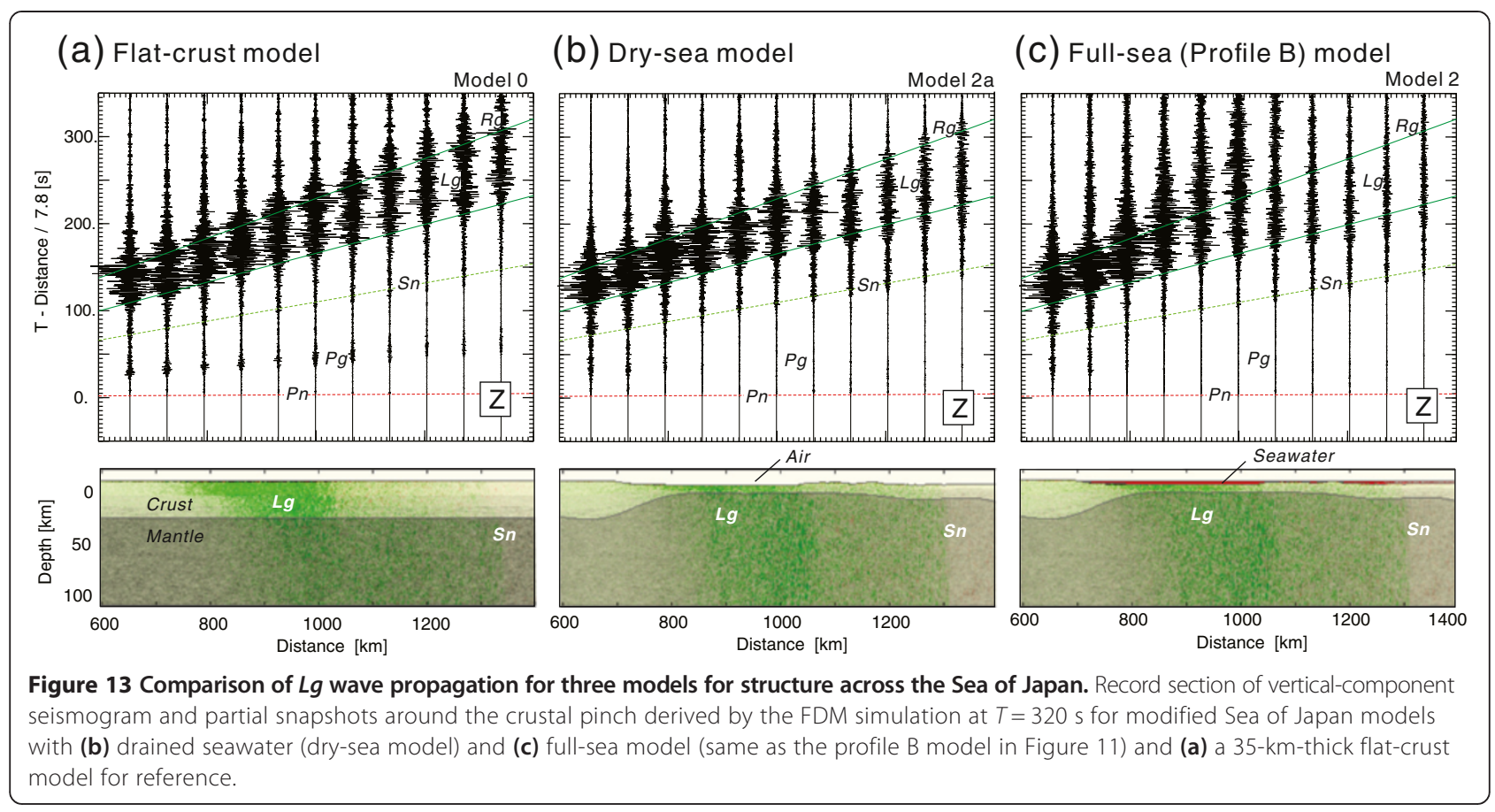

the epicentral distance. This is also due to anelastic attenuation $(Q s)$, which takes the form $\exp \left(-\pi^{*} r /\left(V s^{*} Q s\right)\right)$, where $V s$ is the shear wave speed. The geometrical spreading factor of $r^{-1}$ corresponds to the isotropic spreading of the seismic wave in a homogeneous structure. Since the seismic wavefront in a heterogeneous structure has directional characteristics, the rate at which seismic wave energy spreads is also heterogeneous. The directional energy spreading variation results in smaller (or larger) apparent $Q s$ along the propagation path when the actual geometrical spreading of the $S$ wave is stronger (or weaker) than the conventional geometrical spreading factor $\left(r^{-1}\right)$ in all directions. The drop in the apparent Qs from 400 to 200 corresponds to an increase in the effective geometrical spreading factor from $r^{-0.83}$ to $r^{-1.15}$ in the heterogeneous crustal waveguide at a distance of $1,000 \mathrm{~km}$ (assuming $V s=3.5 \mathrm{~km} / \mathrm{s}$ ).

Nuttli's (1973) geometrical spreading factor of $r^{-0.83}$ for $L g$ wave was derived from a theoretical model of an Airy phase trapped in a homogeneous crustal waveguide with a strong contrast at the Moho. In our case, the $L g$ wave attenuation is much stronger in the heterogeneous and thinner crustal waveguide due to the loss of $L g$ wave energy from the crustal waveguide into the mantle.

As we noted in Figure 11b, the partitioning of the $L g$ wave energy into seawater accelerates the attenuation and elongation of the $L g$ wave train. We examined such effects by comparing the seismogram and attenuation function of the $L g$ wave elastic energy using a modified dry-sea model that excluded seawater (Figure 13b; dry-sea model) and compared the result with the simulation mentioned above (Figure 13c; full-sea model), which is equivalent to the profile B model shown in Figure 10b, and the result for the reference flat-crust model (Figure 13a). We observed $L g$ attenuation and $S n$ development during propagation across a thin crust due to the $L g$-to-Sn phase conversion (Figure 13b). Strong $L g$-to- $P$ conversions at the bottom of the sea and the trapping of $P$ wave energy into seawater (red color in Figure 13c) drastically elongate the later $L g$ wave coda by converting it back into the $S$ wave.

The strength of the $L g$ wave is examined by calculating the strain energy (i.e., $E=1 / 2 \times \rho \times v^{2}$, where $\rho$ is density and $v$ is particle velocity). Figure 14 plots the $L g$ wave train energy measurements derived by the square average sum of $L g$ wave ground velocities for horizontal and vertical motions over the time window for group velocities between 3.5 and $2.8 \mathrm{~km} / \mathrm{s}$. The results show that a large amplitude $L g$ wave develops for epicentral distances above $150 \mathrm{~km}$ and that the energy can be sustained over large distances in a homogeneous crustal waveguide up to an epicentral distance of $700 \mathrm{~km}$, where crust thinning starts. Once crust thinning starts, the $L g$ wave strain energy increases over the epicentral distance range of 700 to $800 \mathrm{~km}$. This is due to the initial concentration of $L g$ wave energy in the thinning crustal structure.

Next, dramatic $L g$ wave attenuation starts with consistent propagation in the thinner crust for epicentral distances from 800 to $1400 \mathrm{~km}$. Thus, after crossing the crustal barrier, the strain energy of the $L g$ wave drops to $10 \%$ of 


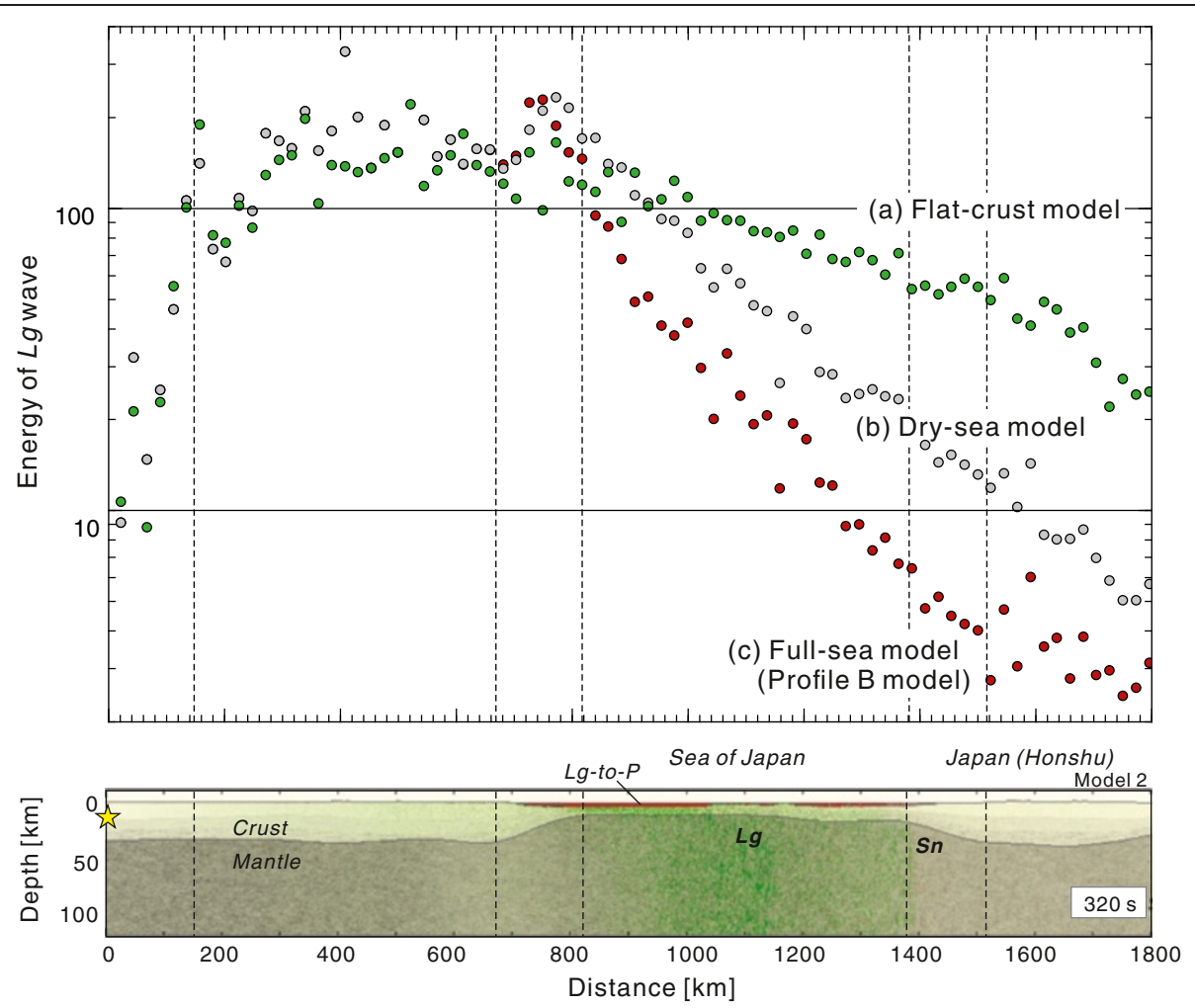

Figure 14 Attenuation function of the $L g$ wave energy for the Sea of Japan structure (Figure 13). Comparison of the attenuation function of the $L g$ wave energy calculated from the synthetic seismograms for the three models in Figure $13 a, b, c$.

the flat-crust model at the distance of $1,500 \mathrm{~km}$. Half of the $L g$ wave energy loss occurs as a result of escaping energy into the mantle during propagation in the thinner crustal waveguide (see the gray points in Figure 14 for the dry-sea model), and the other half of the energy attenuation is associated with transfer of $L g$ wave energy into $P$ waves in seawater (see the red points for the full-sea model). Therefore, we have concluded that both the effects of thinning crust and the presence of seawater are important components of the dramatic loss of $L g$ wave energy that occurs when such waves propagate across the complex crustal barrier.

\section{Discussion}

\section{Magnitude estimation based on $L g$ wave}

The strong variations seen in the $L g$ wave propagation efficiency and inefficiency in the area around Japan, as shown in Figure 7, may cause significant bias for $m b(L g)$ magnitude estimates that are based on $L g$ amplitudes. As we show in Figure 12, the $L g$ amplitude drops across the continental to oceanic transition zone are roughly twice as great as those along the continental path, which would cause underestimation of $m b(L g)$ by a 0.3 magnitude unit when using a magnitude scale function based on $\log (A)$, where $A$ is the amplitude of the $L g$ wave, such as in the scale derived by Nuttli (1973). Hong (2012) pointed out that the estimated $m b(L g)$ for an underground nuclear explosion test conducted by North Korea on 9 October 2006 recorded in stations across the continental margin using an $L g$ wave set produced a smaller $m b(L g)=$ 2.6 to 3.4 than was recorded at stations along continental paths $(m b(L g)=3.8$ to 4.2$)$. Hong (2012) also proposed a correction function for the $m b(L g)$ estimation by employing a ray path-dependent $Q s$, with much lower Qs along the path from the Japanese subduction zone to the Korean Peninsula, rather than using a constant Qs for all earthquakes.

A similar discussion on local magnitude overestimations was made in Furumura and Kennett (2001) and Kennett and Furumura (2002) for the 2000 western Tottori (western Japan) earthquake. In those studies, they pointed out that the Japan Meteorological Agency (JMA) provided a relatively high local magnitude value $\left(M_{\mathrm{IMA}}\right.$ 7.3) compared to the moment magnitude estimated by various other agencies ( $M w 6.6$ to 6.8$)$ and explained this discrepancy as the result of $L g$ and $R g$ wave development in western Japan resulting from the western Tottori earthquake, which carried a large-amplitude seismic wave over long distances with significantly less attenuation than a body $S$ wave. This explanation is consistent with the efficient $L g$ wave propagation noted in the regional distances around Tottori, as shown in Figure 7 . They also noted that 
the magnitude function used by the JMA was derived by Tsuboi (1954) based on the analysis of earthquakes that had occurred mostly in northern Japan, where the $L g$ wave propagation is not as efficient (see Figure 7).

\section{Potential $L g$ wave seismic hazard}

In some areas where the $L g$ propagation is efficient, such as in western Japan, $L g$ waves have the potential ability to carry strong ground motions over significant distances from the source region. The dominant frequency of an $\mathrm{Lg}$ wave, ranging 0.2 to $5 \mathrm{~Hz}$, causes significant resonance with wooden-frame houses and low-rise buildings with fewer than ten floors. The JMA shaking intensity scale is designed to emphasize the strength of ground motions in this frequency range.

Furumura and Kennett (1998) and Furumura and Singh (2002) analyzed seismograms in Mexico City from Mexican subduction zone earthquakes, such as for the 1985 Michoacán earthquake ( $M w$ 8.0) and showed that the $L g$ wave carried large-amplitude ground motions very effectively in the 0.2 - to $0.3-\mathrm{Hz}$ frequency band from the coast to more than $300 \mathrm{~km}$ inland. Therefore, it has been recognized that the dominance in the seismic wave in frequencies around 0.2 to $0.3 \mathrm{~Hz}$ radiating from the source of the 1985 Michoacán earthquake (e.g., Campillo et al. 1989; Singh et al. 1988, 1990) and a dramatic amplification of ground motions in these frequencies due to resonance with the soft reclaimed sediments below the lake-bed zone of Mexico City (e.g., Sánchez-Sesma et al. 1993; Kawase and Aki 1989; Chávez-García and Cuenca 1996) was the major cause of the destructive damage suffered by Mexico City during the 1985 Michoacán earthquake. We also note that in this frequency band, the path effect of efficient seismic wave transportation from the coast to inland for significant distance due to the efficient propagation of $L g$ wave is an important contributor to the large and long-time duration strong ground motions developed in Mexico City. Using FDM simulations, Furumura and Kennett (1998) and Furumura and Singh (2002) demonstrated that the shallowly subducting Cocos plate beneath Mexico reinforced the post-critical $S$ wave reflections between the free surface and the top of the dipping plate interface, thus directing a large amount of $S$ wave energy inland, which then developed a large and elongated $L g$ wave train.

A similar sort of distant and localized damage occurred beside Lake Suwa in central Honshu (see Figure 2) during the 1944 Tonankai earthquake ( $M$ 7.9) that ruptured along the eastern half side of the Nankai Trough at a hypocentral distance of approximately $300 \mathrm{~km}$ (Usami 1996). There is no doubt that strong ground motion amplification in the soft sediments of this lake, like in Mexico City, is the primary cause of the significant damage suffered, but an additional ground motion reinforcement effect due to the shallowly dipping Philippine Sea Plate beneath the Japanese Islands helped direct strong ground motions toward the inland direction in a similar way to that seen in Mexico City (Kennett and Furumura 2002). Furthermore, as we saw in Figure 7, there is a zone of good $L g$ wave propagation from the Nankai Trough to central Japan.

\section{Additional factors affecting $L g$ propagation}

Thus far, this study has focused primarily on the influence of the major features of crustal structure on $\mathrm{Lg}$ propagation and blockage. However, the influence of thick sediment cover over heterogeneous crust could well cause additional $L g$ attenuation effects, and some components of the $L g$ wave propagation variation across Japan might be associated with such thick sediment covers in addition to the crustal thickness changes. In the present large-scale $(1,900 \mathrm{~km} \times 2,000 \mathrm{~km}) 3-\mathrm{D}$ FDM simulation, the implementation of the low-wave speed (e.g., $V \mathrm{~s}<0.5$ $\mathrm{km} / \mathrm{s}$ ) sediments while retaining the same span of frequencies is somewhat difficult, even when the most advanced supercomputers are used. However, the steadily improving state of computer technology should enable such simulations in the near future. In such highresolution simulations, we will also need a detailed model of sedimentary layers that can be produced by combining different data derived by reflection experiments, tomography, etc. Furthermore, so far, we have assumed a constant $Q s$ value in the crust and mantle, but lateral variation of attenuation structure could also cause a strong effect on high-frequency $L g$ wave propagation, such as when the waves cross the volcanic zone in the Tohoku region of Japan.

\section{Conclusions}

We have analyzed a large number of regional waveform records obtained from dense seismic stations in Japan (Hi-net) and in Korea and coupled these observations to large-scale 3-D FDM simulations of regional wavefields using the Earth Simulator supercomputer (The Earth Simulator Center). With the aid of the recently developed CRUST 1.0 model (Laske et al. 2013), we have successfully described the main features of the regional wavefield arising via the crustal structure transitions from continental Asia to the Korean Peninsula, the Japanese subduction zones, and across the Sea of Japan.

Efficient $L g$ wave propagation was found from continental Asia to Kyushu, through the Korean Peninsula, and to Hokkaido. However, the $L g$ propagation to the Japanese main island of Honshu was totally blocked because it crosses the continental to oceanic boundary surrounding the Sea of Japan. The visualized regional wavefield derived from these simulations demonstrates the process of the $L g$ wave suppression by transmission of the $S$ waves into the mantle through the Moho interface and the dissipation of 
the $L g$ energy into seawater by conversion to $P$ wave. Crustal thinning and varying seawater cover were found to extract significant effects on eliminating $L g$ by extracting its energy from the crustal waveguide and by elongating the weaker $L g$ wave train. An investigation into the regional $L g$ wavefield can be expected to provide a key for improving the knowledge about detailed crustal structures and local tectonics.

Efficient $L g$ propagation in relatively homogeneous waveguides, such as from the Asian mainland to Kyushu and Hokkaido and along western Japan, has the potential to carry strong ground motions and produce disasters associated with amplification of ground motion in soft sediments beneath populated cities. Thus, detailed evaluations of the regional variations in $L g$ wave propagation are necessary for evaluating for the causes of strong ground motion damage in past earthquakes and for seismic hazard mitigation efforts in anticipation of future earthquakes.

\section{Competing interests}

The authors declare that they have no competing interests.

\section{Authors' contributions}

TF proposed the topic and carried out the main data analysis and numerical simulations. TKH analyzed data, and BLNK helped with its interpretation. TKH and BLNK collaborated with the corresponding author in the preparation of the manuscript. All authors have read and approved the final manuscript.

\section{Authors' information}

TF is a Professor of the Earthquake Research Institute and the Center for Integrated Disaster Information Research, the University of Tokyo. He received his Ph.D. in Geophysics from Hokkaido University in 1992 and has been working in the field of computer simulations of seismic wave and tsunami propagation, data assimilation, and the visualization of ground motion in order to further understanding of seismic wavefields in heterogeneous structures. He has been a board member of the Japan Geoscience Union (JpGU) since 2008. TKH is an Associate Professor of Geophysics in the Department of Earth System Sciences at Yonsei University. He received his Ph.D. in Geophysics from The Australian National University in 2003. His research interests focus primarily on the investigation of crustal heterogeneities by processing seismic waveform data and analyzing source properties, along with the development and application of numerical techniques for the analysis of seismic wave propagation and scattering in heterogeneous structures. BLNK is a Professor of Seismology at the Research School of Earth Sciences, Australian National University and is the director of the ANSIR National Research Facility of Australia. He is the past President of the International Association of Seismology and Physics of the Earth's Interior (IASPEI) and received his Ph.D. in 1973 from the University of Cambridge. His research interests include the development of interpretational techniques for seismic records with the stated objective of extracting detailed information about the nature of the structure within the Earth and the characteristics of seismic sources.

\section{Acknowledgements}

We would like to thank the National Research Institute for Earth Science and Disaster Prevention (NIED) of Japan for providing Hi-net data, the Korea Meteorological Administration (KMA), the Korea Institute of Geoscience and Mineral Resources (KIGAM), and the US IRIS Data Management Center in Seattle for providing seismic data. We also extend our thanks to the Earth Simulator Center of the Japan Marine Science and Technology Center (JAMSTEC) for providing central processing unit (CPU) time on the Earth Simulator. This study is supported by the Grant-in-Aid for Scientific Research (c) 23540490 from the Japan Society for the Promotion of Science and the Observation and Research Program for Prediction of Earthquakes and Volcanic Eruptions from the Ministry of Education, Culture, Sports, Science, and Technology. The constructive comments received from the three anonymous reviewers and the Editor were very helpful for revising this manuscript.

\section{Author details}

'Earthquake Research Institute, The University of Tokyo, 1-1-1 Yayoi, Bunkyo-ku, Tokyo 113-0032, Japan. '2Department of Earth System Sciences, Yonsei University, 50 Yonsei-ro, Seodaemun-gu, Seoul 120-749, South Korea. ${ }^{3}$ Research School of Earth Sciences, The Australian National University, Canberra ACT 0200, Australia.

Received: 2 December 2013 Accepted: 27 April 2014

Published: 21 May 2014

\section{References}

Aki K, Chouet B (1975) Origin of coda waves: source, attenuation, and scattering effects. J Geophys Res 80:3322-3342

Azuma H, Kawai S, Fujiwara H (2013) Development of J-SHIS and applications using API. J Disast Res 8:869-877

Baumgardt DR (1985) Attenuation, blockage, and scattering of teleseismic Lg from underground nuclear explosions in Eurasia. AFGL-TR-85-0332, ENSCO, Inc, Virginia

Campillo M (1987) Lg wave propagation in a laterally varying crust and the spatial distribution of the quality factor in central France. J Geophys Res 92:12604-12614

Campillo M, Gariel JC, Aki K, Sánchez-Sesma FJ (1989) Destructive strong ground motion in Mexico City: source, path and site effects during great 1985 Michoacán earthquake. Bull Seism Soc Am 79:1718-1735

Chang SJ, Baag CE (2005) Crustal structure in southern Korea from joint analysis of teleseismic receiver functions and surface-wave dispersion. Bull Seism Soc Am 95:1516-1534

Chávez-García FJ, Cuenca J (1996) Site effects in Mexico City urban zone: a complementary study. Soil Dyn Earthq Eng 15:141-146

Chung TW, Noh MH, Kim JK, Park YK, Yoo HJ, Lees JM (2007) A study of the regional variation of low-frequency $Q_{L g}$ around the Korean peninsula. Bull Seism Soc Am 97:2190-2197

Fan GW, Lay T (2003) Strong Lg attenuation in the Tibetan plateau. Bull Seism Soc Am 93:2264-2272

Fisk MD (2006) Source spectral modeling of regional P/S discriminants at nuclear test sites in China and the former Soviet Union. Bull Seism Soc Am 96:2348-2367

Furumura T, Kennett BLN (1998) On the nature of regional seismic phases III: the influence of crustal heterogeneity on the wavefield for subduction earthquakes: the 1985 Michoacán and 1995 Copala, Guerrero, Mexico earthquakes. Geophys J Int 135:1060-1084

Furumura T, Kennett BLN (2001) Variations in regional phase propagation in the region around Japan. Bull Seism Soc Am 91:668-682

Furumura T, Singh SK (2002) Regional wave propagation from Mexican subduction zone earthquakes: the attenuation functions for interplate and inslab events. Bull Seism Soc Am 92:2110-2125

Gregersen S (1984) Lg wave propagation and crustal structure differences near Denmark and the North Sea. Geophys J R Astron Soc 79:217-234

Herrmann RB, Nuttli OW (1982) Magnitude: the relation of $M_{L}$ to $m b_{L g}$. Bull Seism Soc Am 72:389-397

Hirata N, Karp BY, Yamaguchi T, Kanazawa T, Suyehiro K, Kasahara J, Shiobara H, Shinohara M, Kinoshita H (1992) Oceanic crust in the Japan Basin of the Japan Sea by the 1990 Japan-USSR expedition. Geophys Res Lett 19:2027-2030

Hong TK (2010) Lg attenuation in a region with both continental and oceanic environments. Bull Seism Soc Am 100:851-858

Hong TK (2012) Lg body-wave magnitude scaling for the continental margin around Korea and Japan. Pure Appl Geophys 169:641-658

Hong TK, Baag CE, Choi H, Sheen DH (2008) Regional seismic observations of the 9 October 2006 underground nuclear explosion in North Korea and the influence of crustal structure on regional phases. J Geophys Res 113:B03305. doi:10.1029/2007JB004950

Kadinsky-Cade K, Barazangi M, Oliver J, Isacks B (1981) Lateral variations in high-frequency seismic wave propagation at regional distances across the Turkish and Iranian plateaus. J Geophys Res 86:9377-9396

Kak AC, Slaney M (1987) Principles of computerized tomographic imaging. IEEE, Piscataway

Kawase H, Aki K (1989) A study on the response of a soft basin for incident S, P, and Rayleigh waves with spectral reference to the long duration observed in Mexico City. Bull Seism Soc Am 79:1361-1382 
Kennett BLN (1993) The distance dependence of regional phase discriminants. Bull Seism Soc Am 83:1155-1166

Kennett BLN, Furumura T (2001) Regional phases in continental and oceanic environments. Geophys J Int 146:562-568

Kennett BLN, Furumura T (2002) The influence of 3-D structure on the propagation of seismic waves away from earthquakes. Pure Appl Geophys 159:2113-2131

Kennett BLN, Gregersen S, Mykkeltveit S, Newmark R (1985) Mapping of crustal heterogeneity in the North Sea basin via the propagation of $\mathrm{Lg}$ waves. Geophys J R Astron Soc 83:299-306

Kim WY, Richards PG (2007) North Korean nuclear test: seismic discrimination at low yield. Eos 14:157-161

Kurashimo E, Shinohara M, Suyehiro K, Kasahara J, Hirata N (1996) Seismic evidence for stretched continental crust in the Japan Sea. Geophys Res Lett 23:3067-3070

Lallemand S, Jolivet L (1985) Japan Sea: a pull-apart basin? Earth Planet Sci Lett 76:375-389

Laske G, Masters G, Ma Z, Pasyanos M (2013) Update on CRUST 1.0: a 1-degree global model of Earth's crust. Geophys Res Abstr 15:EGU2013-EGU2658

Maupin V (1989) Numerical modelling of $L g$ wave propagation across the North Sea Central Graben. Geophys J Int 99:273-283

Nakamura R, Uetake T (2002) Three-dimensional attenuation structure and site amplification inversion by using a large quantity of seismic strong motion records in Japan. Zisin II 54:475-488 (in Japanese with English abstract)

$\mathrm{Ni}$ J, Barazangi M (1983) High frequency seismic wave propagation beneath the Indian shield, Himalayan Arc, Tibetan Plateau, and surrounding regions: high uppermost mantle velocities and efficient $S n$ propagation beneath Tibet. Geophys J R Astron Soc 72:655-689

Nuttli OW (1973) Seismic wave attenuation and magnitude relations for eastern North America. J Geophys Res 78:876-885

Obara K, Kasahara K, Hori S, Okada Y (2005) A densely distributed high-sensitivity seismograph network in Japan: Hi-net by National Research Institute for Earth Science and Disaster Prevention. Rev Sci Instrum 76:021301. doi:10.1063/1.1854197

Okada Y, Kasahara K, Hori S, Obara K, Sekiguchi S, Fujiwara H, Yamamoto A (2004) Recent progress of seismic observation networks in Japan-Hi-net, F-net, K-NET and KiK-net. Earth Planets Space 56:15-28

Olsen KH, Braile LW, Stewart JN (1983) Modeling short-period crustal phases $(P, L g)$ for long-range refraction profiles. Phys Earth Planet Int 32:334-347

Otofuji Y, Itaya Y, Matsuda T (1991) Rapid rotation of southwest Japan: paleomagnetism and K-Ar ages of Miocene volcanic rocks of southwest Japan. Geophys J Int 105:397-405

Park JH, Chi HC, Lim IS, Kim GY (2009) Korea seismic networks and Korea Integrated Seismic System (KISS). Geophys Res Abstr 11:EGU2009-EGU9191

Phillips WS, Hartse HE, Taylor SR, Randall GE (2000) $1 \mathrm{~Hz}$ Lg tomography in Central Asia. Geophys Res Lett 27:3425-3428

Press F, Ewing M (1952) Two slow surface waves across North America. Bull Seism Soc Am 42:219-228

Robertsson JOA, Blanch JO, Symes WW (1994) Viscoelastic finite-difference modeling. Geophysics 59:1444-1456

Rodgers AJ, Ni JF, Hearn TM (1997) Propagation characteristics of short-period Sn and $L g$ in the Middle East. Bull Seism Soc Am 87:396-413

Ruzaikan Al, Nersesov IL, Khalturin VI, Molnar P (1977) Propagation of L $g$ and lateral variation in crustal structure in Asia. Geophys J R Astron Soc 82:307-316

Ryoki K (1999) Three-dimensional depth structure of the crust and uppermost mantle beneath southwestern Japan and its regional gravity anomalies. Zisin || 52:51-63 (in Japanese with English abstract)

Sánchez-Sesma FJ, Pérez-Rocha LE, Reinoso E (1993) Ground motion in Mexico City during the April 25, 1989, Guerrero earthquake. Tectonophysics 218:127-140

Sekine S (2005) Tomographic inversion of ground motion amplitudes for the 3-D attenuation structure beneath the Japanese islands. Report Nat Res Institute Earth Sci Disaster Prev 68:137-174

Shima H (1962) On the velocity of $\mathrm{Lg}$ waves in Japan. Quart J Seismol 27:1-6 (in Japanese with English abstract)

Sing SK, Mena E, Castro R (1988) Some aspects of source characteristics of the 19 September 1985 Michoacán earthquake and ground motion in and near Mexico City from strong motion data. Bull Seism Soc Am 78:451-477

Singh SK, Mori A, Mena E, Krüger F, Kind R (1990) Evidence for anomalous body-wave radiation between 0.3 and $0.7 \mathrm{~Hz}$ from the 1985 September 19 Michoacán, Mexico earthquake. Geophys J Int 101:37-48
Singh C, Shekar M, Singh A, Chadha RK (2012) Seismic attenuation characteristics along the Hi-CLIMB profile in Tibet from $\mathrm{Lg}$ Q inversion. Bull Seism Soc Am 102:783-789

Taylor S (1996) Analysis of high-frequency Pg/Lg ratios from NTS explosions and western U.S. earthquakes. Bull Seism Soc Am 86:1042-1053

Tsuboi C (1954) Determination of the Gutenberg-Richter's magnitude of earthquakes occurring in and near Japan. Zisin II 7:185-193 (in Japanese with English abstract)

Usami T (1996) Materials for comprehensive list of destructive earthquakes in Japan. Revised and enlarged edition. University of Tokyo Press, Tokyo, pp 294-295 (in Japanese)

Utsu T (1956) On some remarkable phases on seismograms of near earthquakes (part 2). Quart I Seismol 21:107-111 (in Japanese with English abstract)

Utsu T (1958) On the Lg phase of seismic waves observed in Japan. Quart J Seismol 23:61-76 (in Japanese with English abstract)

Walter WR, Mayeda K, Patton HJ (1995) Phase and spectral ratio discrimination between NTS earthquakes and explosions: part 1: empirical observations. Bull Seism Soc Am 85:1050-1067

Xie J (2002) Lg Q in the eastern Tibetan Plateau. Bull Seism Soc Am 92:871-876

Xie J, Wu Z, Liu R, Schaff D, Liu Y, Liang J (2006) Tomographic regionalization of crustal L $\mathrm{Q} Q$ in eastern Eurasia. Geophys Res Lett 33:L03315. doi:10.1029/2005GL024410

Yomogida K (1996) J-array: deep structure of the Earth. J Phys Earth 44:655-656

doi:10.1186/2197-4284-1-10

Cite this article as: Furumura et al.: $L g$ wave propagation in the area around Japan: observations and simulations. Progress in Earth and Planetary Science 2014 1:10

\section{Submit your manuscript to a SpringerOpen ${ }^{\circ}$ journal and benefit from:}

- Convenient online submission

- Rigorous peer review

- Immediate publication on acceptance

- Open access: articles freely available online

- High visibility within the field

- Retaining the copyright to your article

Submit your next manuscript at $\gg$ springeropen.com 